\title{
Human Capital Accumulation and the Macroeconomy in an Ageing Society
}

\author{
Ben J. Heijdra ${ }^{1,2,3}$ - Laurie S. M. Reijnders ${ }^{1,3}$
}

Published online: 10 August 2016

(c) The Author(s) 2016. This article is published with open access at Springerlink.com

\begin{abstract}
How do population ageing shocks affect the long-run macroeconomic performance of an economy? To answer this question we build a general equilibrium overlapping generations model of a closed economy featuring endogenous factor prices. Finitely-lived individuals are endowed with perfect foresight and make optimal choices over the life cycle. In addition to selecting age profiles for consumption and the hours of time supplied to the labour market, they also choose their schooling level and retirement age. Human capital is accumulated as a result of work experience, the extent of which is determined by the intensity of labour supply. As the agent gets older, biological deterioration sets in and human capital depreciates at an increasing rate. This ultimately prompts the agent to withdraw from the labour market. The micro-
\end{abstract}

\footnotetext{
We are much indebted to Fabian Kindermann for computational advice on efficient Matlab and Fortran programming, and to Jochen Mierau for providing us with a detailed survey of the human capital literature. This paper was presented at the Bogazici Dynamic Macro Workshop (May 2012, Bogazici University, Istanbul), the 12th Viennese Workshop on Optimal Control, Dynamic Games and Nonlinear Dynamics (June 2012, Vienna), the CESifo Conference of Public Sector Economics (April 2013, Munich), CEF 2012 (July 2013, Vancouver), SAET (July 2013, Paris), ESEM (August 2013, Gothenburg), and at seminars at the Universities of Groningen, Hong Kong, and Paris I. We thank Hippolyte d'Albis, Henning Bohn, Scott Findley, Fabian Kindermann, Sau-Him Lau, Jochen Mierau, Petros Milionis, Steve Turnovsky and various conference and seminar participants for their useful comments.
}

$\bowtie \quad$ Ben J. Heijdra

b.j.heijdra@rug.nl

Laurie S. M. Reijnders

1.s.m.reijnders@ rug.nl

1 Faculty of Economics and Business, University of Groningen, P.O. Box 800, 9700 AV

Groningen, The Netherlands

2 CESifo, Munich, Germany

3 Netspar, Tilburg, The Netherlands 
economic and macroeconomic effects of three ageing shocks are studied, namely an increase in the length of biological life (biological longevity boost), an increase in both biological and productive life span (comprehensive longevity boost), and a decrease in the net birth rate (baby bust). Robustness checks are performed by allowing for capital market imperfections and indivisibility of labour supply.

Keywords Human capital - Education - Experience effects - Borrowing constraints . Indivisible labour · Retirement · Overlapping generations · Demography

JEL Classification E10 $\cdot$ D91 $\cdot \mathrm{O} 40 \cdot \mathrm{F} 41 \cdot \mathrm{J} 11$

\section{Introduction}

By the time you are eighty years old you've learned everything. You only have to remember it. George Burns (1896-1996)

Over the last half century most advanced economies have experienced substantial demographic changes leading to an overall ageing of the population. Table 1 provides some data for the nine economically most important OECD economies. For each country the first row gives the crude birth rate expressed per one hundred members of the total population. In the immediate post-war period these economies typically had relatively high fertility rates with Canada even realizing a birth rate of almost 3 per hunfred in the period 1950-1955. After the 1960s, however, a downward trend in the crude birth rate is clearly visible in many of these countries. The most recent figures show that the fertility rate ranges between 0.8 and 1.4 .

In addition to this baby bust, these same countries have also experienced an increase in life expectancy. For each country the second row gives the data for life expectancy at birth. The increase in biological longevity is nothing short of spectacular. Whereas in the 1950s life expectancy in all but one of the OECD countries was below 70 years, at the end of the sample period it ranges between 78 and 82.7 years. So in the interval of six decades advances in medical technology and increased hygiene have managed to increase individuals' length of life by roughly 10 years.

The combination of a falling birth rate and increased longevity has led to an ageing of the population. The third row for each country provides a simple measure for the age composition of the population. This is the old-age dependency ratio which represents the fraction of old people (65 years and older) to people of working age (ages between 20 and 64). Whereas this ratio ranged between 10 and $14 \%$ for most countries in the early 1950s, at the start of the twenty-first century it lies between 20.5 and $32.5 \%$.

The objective of this paper is to study the macroeconomic general equilibrium effects of the demographic shocks mentioned above. Since these shocks affect the richest countries in the world in a more or less similar fashion we adopt a closed economy perspective, i.e. factor price changes form an important mechanism by which ageing affects the macroeconomic outcome. To keep the analysis tractable we restrict 
Table 1 Demographic indicators for large OECD countries. Source: United Nations (2011)

\begin{tabular}{|c|c|c|c|c|c|c|c|}
\hline & 1950 & 1960 & 1970 & 1980 & 1990 & 2000 & 2005 \\
\hline \multirow[t]{3}{*}{ United States } & 2.4 & 2.2 & 1.6 & 1.5 & 1.5 & 1.4 & 1.1 \\
\hline & 68.6 & 70.2 & 71.5 & 74.5 & 75.6 & 77.2 & 78.0 \\
\hline & 14.3 & 17.5 & 18.7 & 19.8 & 21.3 & 21.0 & 20.5 \\
\hline \multirow[t]{3}{*}{ Japan } & 2.4 & 1.7 & 1.9 & 1.3 & 1.0 & 0.9 & 0.9 \\
\hline & 62.2 & 69.0 & 73.1 & 77.0 & 79.5 & 81.8 & 82.7 \\
\hline & 10.0 & 10.6 & 11.7 & 15.0 & 19.4 & 27.6 & 32.5 \\
\hline \multirow[t]{3}{*}{ Germany } & 1.6 & 1.8 & 1.1 & 1.1 & 1.0 & 0.9 & 0.8 \\
\hline & 69.5 & 70.3 & 71.0 & 73.8 & 76.0 & 78.7 & 79.9 \\
\hline & 16.2 & 19.2 & 24.3 & 27.2 & 23.5 & 26.1 & 31.4 \\
\hline \multirow[t]{3}{*}{ France } & 1.9 & 1.8 & 1.6 & 1.4 & 1.3 & 1.3 & 1.3 \\
\hline & 67.3 & 70.8 & 72.4 & 74.8 & 77.4 & 79.6 & 81.0 \\
\hline & 19.5 & 20.8 & 23.8 & 25.0 & 24.0 & 27.5 & 28.0 \\
\hline \multirow[t]{3}{*}{ United Kingdom } & 1.5 & 1.8 & 1.4 & 1.3 & 1.3 & 1.1 & 1.2 \\
\hline & 69.3 & 71.0 & 72.2 & 74.1 & 76.2 & 78.4 & 79.6 \\
\hline & 17.9 & 20.2 & 23.3 & 26.8 & 26.9 & 26.8 & 26.9 \\
\hline \multirow[t]{3}{*}{ Italy } & 1.8 & 1.8 & 1.6 & 1.1 & 1.0 & 0.9 & 0.9 \\
\hline & 66.3 & 69.6 & 72.1 & 74.8 & 77.4 & 80.2 & 81.4 \\
\hline & 14.3 & 16.4 & 19.4 & 23.7 & 24.5 & 29.4 & 32.0 \\
\hline \multirow[t]{3}{*}{ Canada } & 2.8 & 2.5 & 1.6 & 1.5 & 1.4 & 1.1 & 1.1 \\
\hline & 69.0 & 71.3 & 73.0 & 75.8 & 77.8 & 79.7 & 80.5 \\
\hline & 14.0 & 14.6 & 15.1 & 16.2 & 18.5 & 20.4 & 20.9 \\
\hline \multirow[t]{3}{*}{ Australia } & 2.3 & 2.2 & 2.0 & 5.5 & 1.5 & 1.3 & 1.4 \\
\hline & 69.3 & 70.9 & 71.7 & 75.1 & 77.5 & 80.3 & 81.4 \\
\hline & 14.0 & 15.9 & 15.5 & 17.1 & 19.1 & 20.8 & 21.4 \\
\hline \multirow[t]{3}{*}{ Netherlands } & 2.2 & 2.1 & 1.5 & 1.2 & 1.3 & 1.2 & 1.1 \\
\hline & 71.9 & 73.5 & 74.1 & 76.1 & 77.3 & 78.7 & 80.2 \\
\hline & 14.0 & 16.8 & 18.8 & 20.0 & 20.8 & 21.9 & 22.8 \\
\hline
\end{tabular}

World Population Prospects: The 2010 Revision, Files 3, 5-1, and 5-3B. First row: crude birth rate (births per 100 population). Second row: life expectancy at birth. Third row: old-age dependency ratio (population of $65^{+}$as a fraction of population 20-64). Rows 1-2 are averages over the 5-year interval starting in year as indicated. Row 3 is the observation in the indicated year

attention to the long-run effects of the demographic changes only-the transitional dynamics associated with these shocks are not considered here. ${ }^{1}$

We formulate an overlapping generations model populated by finitely-lived, utilitymaximizing individuals who are blessed with perfect foresight. At each moment in time, disconnected generations are born. We abstract from mortality risk and use a generalized version of the classic "certain death" model of Cass and Yaari (1967).

\footnotetext{
1 In Heijdra et al. (2014a) we build a stochastic version of the model featuring uninsured idiosyncratic risk. We use this model to study the transitional and long-run effects of changes in the system of study loans.
} 
We extend their model inter alia by assuming that individual agents accumulate both physical and human capital.

Whereas biological longevity is represented in our model by the length of time that an agent is alive, we view economic longevity as the life spell during which the agent is economically productive. In particular it is an aspect of the endogenous life-cycle pattern of the stock of embodied human capital that an individual can rent out to producers in the labour market. We operationalize the concept of economic longevity as follows. In the tradition of the recent macroeconomic literature on human capital accumulation we assume that individuals engage in full-time educational activities at the start of economic life and choose the optimal age of labour market entry (KalemliOzcan et al. 2000; Boucekkine et al. 2002; Heijdra and Romp 2009). Incorporating the insights of the empirical labour economics literature on Mincerian wage equations, we assume that participating in the labour market boosts a worker's human capital stock and wage income as valuable experience is gained (cf. Imai and Keane 2004). As a worker gets older, economic ageing sets in because human capital starts to depreciate at an increasing rate- the ageing phenomenon aptly verbalized by Burns in the opening quote above.

We stress from the outset that our approach is predominantly a theoretical one, i.e. we construct a highly stylized model and focus our attention on the key mechanisms at work which we visualize with the aid of a plausibly parameterized version of the model. Put differently, in order to zoom in on the pure effects of biological and economic ageing we deliberately leave out a number of real-life features and institutions that are typically included in simulation-based models in order to achieve a convincing calibration. For example, we model an economy without a pension system, recognize only one ability type (all workers are college educated), and ignore (uninsured) longevity risk. In a related paper we focus exactly on these three real-world features and calibrate the model for the United States (see Heijdra and Reijnders 2015).

The microeconomic and macroeconomic effects of three stylized demographic shocks are studied. The first shock is a biological longevity boost, consisting of a substantial increase in the length of life accompanied by a constant population growth rate and an unchanged human capital depreciation schedule. The second shock is called a comprehensive longevity boost. This case combines the biological longevity boost with an increase in economic longevity which we operationalize as an outward shift of the depreciation schedule for human capital. Finally, the third shock is a pure baby bust scenario, in which the net birth falls but the length of biological and economic life both remain unchanged.

Our main findings are as follows. As a result of a biological longevity boost, agents respond to the longer lifetime by choosing slightly more schooling, retiring somewhat later, and marginally increasing the length of the work career. Almost all of the additional years of life are consumed in the form of leisure as the retirement period increases substantially. Matters are quite different under a comprehensive longevity boost. In this case the stocks of physical and human capital both rise sharply, with the latter increase dominating the former. Schooling is increased only slightly, but as retirement takes place much later on in life the length of the work career rises dramatically. Surprisingly, the optimal retirement period is decreased under this shock, i.e. 
the additional years of biological life are not spent on leisure but on working. Finally, a baby bust shock results in a slight increase in the physical capital stock accompanied by a decrease in the stock of human capital and a small reduction in macroeconomic output. We also show that all these conclusions are robust to real world complications such as capital market imperfections and indivisible labour contracts.

Our paper is intended as a contribution to the extensive literature on the macroeconomics of ageing. One strand of this literature studies ageing shocks using models in which physical capital is the only accumulable production input. For recent examples, see Heijdra and Ligthart (2006), Bloom et al. (2007), Prettner and Canning (2014), and the references accompanying these papers. There is a large diversity of models, depending on inter alia the endogeneity or exogeneity of the agent's labour market retirement decision and the inclusion or exclusion of a public pension system. But the typical conclusion that emerges from these physical-capital-only models is that ageing results in an increase in the capital intensity of production accompanied by an increase in real wages and a drop in the real rate of return on physical capital.

A second, more recent strand of the literature adds human capital as an additional accumulable production factor. See, for example, Kalemli-Ozcan et al. (2000), Heijdra and Romp (2009), and Ludwig et al. (2012) and the references therein. One of the key features common to all these models is the endogeneity of the agent's schooling decision. Again many different model varieties exist, depending on the assumptions made regarding retirement and public pension systems. The typical conclusion resulting from these human-plus-physical-capital models is that a longevity shock raises both stocks, but still increases the ratio of physical to human capital employed in production, though by a smaller amount than is the case in models without human capital—see, for example, Kalemli-Ozcan et al. (2000, p. 15) and Ludwig et al. (2012, p. 106).

In contrast to both strands of the literature mentioned above, in our model we find that the increase in human capital dominates the boost to physical capital under the comprehensive longevity boost so that ageing leads to a lower wage and a higher real interest rate. By separately distinguishing biological and economic longevity we are thus able to demonstrate that factor prices may move in a direction opposite to the one accepted as conventional wisdom in the existing literature. Just looking at biological age may be highly misleading: individuals may live longer but their human capital may not. Indeed, the clear message from this predominantly theoretical paper is the need for empirical information regarding the age profile of productivity at older ages.

The remainder of this paper is organized as follows. In Sect. 2 we formulate our base model. Section 3 uses a parameterized version of the model to compute and visualize the microeconomic and macroeconomic effects of stylized shocks in biological and economic longevity and the net birth rate. Section 4 investigates the robustness of our conclusions by including capital market imperfections in the form of borrowing constraints and labour market imperfections resulting from the indivisibility of labour. Section 5 summarizes and concludes. A brief appendix establishes some technical results. 


\section{Model}

In this section we develop a dynamic microfounded general equilibrium model of a closed economy featuring exogenous growth. All agents in the economy are endowed with perfect foresight. The population is made up of overlapping generations of finitely-lived agents who make optimal decisions over the life cycle. There is no longevity risk. ${ }^{2}$ Firms use stocks of physical and human capital in order to produce the homogeneous good. Individuals accumulate the two types of capital by saving, by enjoying formal education at the start of economic life, and by gaining experience on the work floor. In the first two subsections we discuss the optimal decisions made by firms and individuals, and in the final subsection we characterize the steady-state macroeconomic equilibrium.

\subsection{Firms}

Technology features constant returns to scale, the goods market is perfectly competitive, and we postulate the existence of a single representative firm facing a linear homogeneous production function of the Cobb-Douglas form:

$$
Y(t)=\Omega_{0} K(t)^{\varepsilon_{k}}[Z(t) H C(t)]^{1-\varepsilon_{k}}, \quad 0<\varepsilon_{k}<1, \quad \Omega_{0}>0
$$

where $Y(t)$ is aggregate output, $Z(t)=Z e^{g t}$ represents Harrod-neutral technological progress, $g$ is the exogenous growth rate $(g \geq 0)$, and $K(t)$ and $H C(t)$ stand for the inputs of, respectively, physical and human capital. Aggregate profit is given by:

$$
\Pi(t) \equiv Y(t)-w(t) H C(t)-\left(r(t)+\delta_{k}\right) K(t),
$$

where $r(t)$ is the real interest rate, $\delta_{k}$ is the constant depreciation rate of physical capital, and $w(t)$ is the rental rate on standardized units of human capital. The firm chooses its inputs $K(t)$ and $H C(t)$ in order to maximize profits. This gives the usual marginal productivity conditions:

$$
\begin{aligned}
r(t)+\delta_{k} & =\varepsilon_{k} \Omega_{0}\left(\frac{k(t)}{h c(t)}\right)^{-\left(1-\varepsilon_{k}\right)}, \\
\tilde{w}(t) & \equiv \frac{w(t)}{Z(t)}=\left(1-\varepsilon_{k}\right) \Omega_{0}\left(\frac{k(t)}{h c(t)}\right)^{\varepsilon_{k}},
\end{aligned}
$$

\footnotetext{
2 By postulating a rectangular mortality profile we are able to sidestep troublesome issues relating to annuitization that are tangential to the topic of this paper. Indeed, in the presence of longevity risk, economic theory strongly predicts that full annuitization of assets is optimal to an individual. In reality, however, people hardly buy annuities at all-the so-called "annuity puzzle". In the absence of annuities, uninsured agents leave accidental bequests which—in the context of a general equilibrium model—must be redistributed somehow. Ludwig et al., for example, assume that these bequests are transferred in equal amounts to all surviving agents (2012, p. 97). As is shown in Heijdra et al. (2014b), however, the specific age-profile of transfers exerts a major influence on allocation and welfare effects.
} 
where $k(t) \equiv K(t) /[P(t) Z(t)], h c(t) \equiv H C(t) / P(t)$, and $P(t)$ is the total population (see below). Profits are equal to zero as a result of the linear homogeneity of the production technology.

In the remainder of the paper we restrict attention to the balanced growth path for which $h c(t)=h c, k(t)=k, r(t)=r, \tilde{w}(t) \equiv \tilde{w}$, and $y(t) \equiv Y(t) /[P(t) Z(t)]=y$ are all time-invariant, and the rental rate on human capital grows exponentially at the constant rate $g$, i.e. $w(t)=w(v) e^{g(t-v)}$.

\subsection{Individuals}

We follow Cass and Yaari (1967) by assuming that individuals have finite lives but experience no longevity risk. The lifetime utility function of a vintage- $v$ newborn is given by:

$$
\Lambda(v) \equiv \int_{v}^{v+D_{b}} \Phi(c(v, t), z(v, t)) e^{-\rho(t-v)} d t,
$$

where $\Phi(\cdot)$ is instantaneous utility (or " felicity"), $c(v, t)$ is consumption of a person of vintage $v$ at time $t, z(v, t)$ is leisure, $\rho$ is the pure rate of time preference, and $D_{b}$ is the age at which sudden biological death occurs. The felicity function takes the following convenient form:

$$
\Phi(c(v, t), z(v, t)) \equiv \frac{\left(c(v, t)^{1-\varepsilon_{z}} z(v, t)^{\varepsilon_{z}}\right)^{1-1 / \sigma}-1}{1-1 / \sigma}
$$

with $0<\varepsilon_{z}<1$ and $0<\sigma<1$. The parameter $\sigma$ represents the intertemporal substitution elasticity for subfelicity which itself is a Cobb-Douglas function of consumption and leisure, i.e. the intratemporal substitution elasticity between consumption and leisure is equal to unity. Although our theoretical expressions are valid for values of $\sigma$ exceeding unity, we restrict attention in this paper to the empirically plausible case featuring $0<\sigma<1$ for which case consumption and leisure are direct substitutes (see Lemma 1 in the "Appendix 1").

The accumulation of financial assets, $a(v, t)$, proceeds according to:

$$
\dot{a}(v, t)=r a(v, t)+w(t) l(v, t) h(v, t)-c(v, t),
$$

where $\dot{a}(v, t) \equiv d a(v, t) / d t$ is net asset accumulation, $l(v, t)$ is labour supply, and $h(v, t)$ is the stock of human capital. In the absence of a bequest motive, individuals are born without any financial assets $(a(v, v)=0)$ and will choose to expire bare of such assets as well $\left(a\left(v, v+D_{b}\right)=0\right)$. It thus follows that in the presence of perfect capital markets the lifetime budget constraint is given by:

$$
\int_{v}^{v+D_{b}} w(t) l(v, t) h(v, t) e^{-r(t-v)} d t=\int_{v}^{v+D_{b}} c(v, t) e^{-r(t-v)} d t .
$$


The accumulation of human capital, $h(v, t)$, depends critically on the use of time over the life cycle. ${ }^{3}$ The agent's choices of $E$ and $R$ constitute important life-cycle decisions. The time line of a person's life takes the following form.

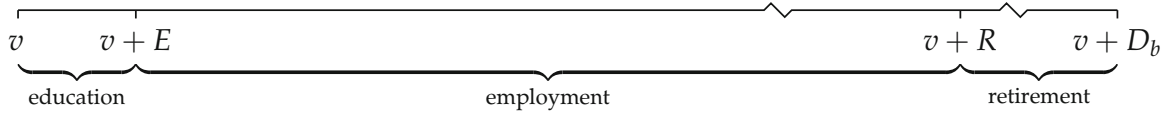

Throughout life the individual has a time endowment of one unit. At the start of economic life, for ages $0 \leq t-v<E$, the individual does not supply any labour to the market $(l(v, t)=0)$ but engages in full-time training which we take to involve $e_{0}$ units of time. Startup education and working in the market are thus modeled as mutually exclusive activities. ${ }^{4}$ Assuming that the individual chooses schooling $E$ and decides to retire from the labour force at age $R$, it follows that leisure is given by:

$$
z(v, t) \equiv \begin{cases}1-e_{0} & \text { for } 0 \leq t-v<E \\ 1-l(v, t) & \text { for } E \leq t-v<R \\ 1 & \text { for } R \leq t-v \leq D_{b}\end{cases}
$$

Depending on the length of the schooling period, the agent enters the labour market with a stock of marketable human capital equal to:

$$
h(v, v+E)=e^{G(E)},
$$

where $G(E)$ is a function such that there exist positive but diminishing returns to education $\left(\partial h(v, v+E) / \partial E>0\right.$ and $\left.\partial^{2} h(v, v+E) / \partial E^{2}<0\right)$. See Fig. 1a for an illustration of the training function that we use in our quantitative analysis below.

Following labour market entry at age $t-v=E$, the individual starts accumulating human according to the following schedule:

$$
\dot{h}(v, t)=\left[\gamma l(v, t)-\delta_{h}(t-v)\right] h(v, t), \quad \text { for } E \leq t-v \leq D_{b}, \quad \gamma>0,
$$

where $\delta_{h}(t-v)$ is the age-dependent depreciation rate of human capital. The accumulation function combines two distinct mechanisms. First, by working in the market the agent gains experience which we assume to be proportional to the number of hours worked times the available stock of human capital, i.e. a smart worker gains more experience per unit of work time than a less accomplished colleague and the higher is labour supply the larger is the gain per unit of available human capital. The parameter $\gamma$ regulates the strength of this experience effect. ${ }^{5}$ The second mechanism captures

\footnotetext{
3 Following the seminal paper by Ben-Porath (1967), a large literature on endogenous human capital formation has emerged. Key contributions are by Weiss (1972), Rosen (1972), Blinder and Weiss (1976), Heckman (1976), and Driffill (1980).

4 The assumption of a start-up education phase of endogenous length is a standard one in the macroeconomic literature. See, for example, de la Croix and Licandro (1999), Kalemli-Ozcan et al. (2000), Boucekkine et al. (2002), and Heijdra and Romp (2009).

5 In early contributions to the human capital literature, Weiss (1972) and Rosen (1972) stress the importance of work experience (or learning-by-doing) effects. Subsequent contributions were made by inter alia
} 

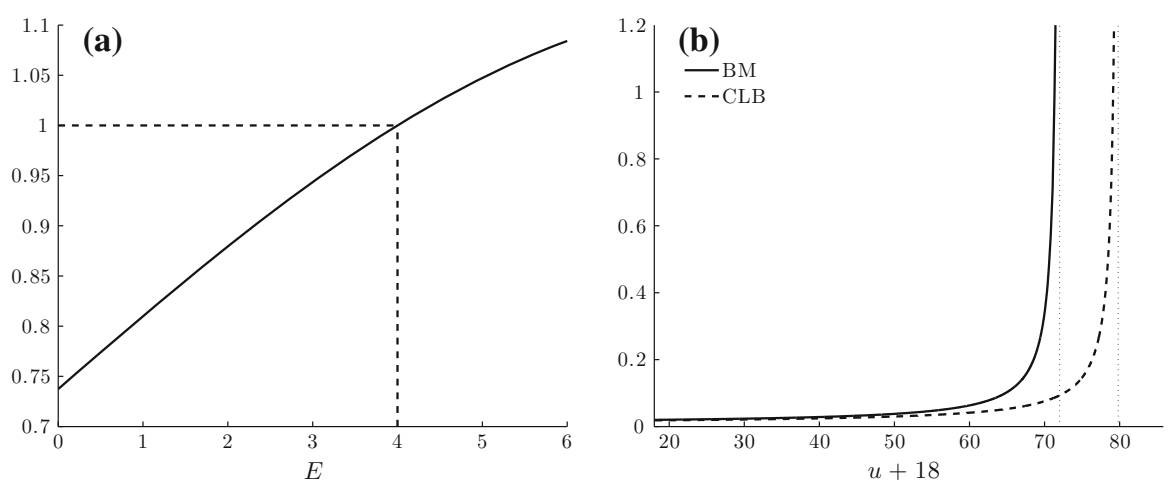

Fig. 1 Features of the human capital accumulation process. a Training function, $e^{G(E)}$. b depreciation rate, $\delta_{h}(u)$. For the training function we postulate $G(E)=\beta_{0}+\beta_{1} E-\beta_{2} E^{2}$ whilst for the human capital depreciation function we use $\delta_{h}(u)=\delta_{0}+\frac{1}{\delta_{1}\left(D_{e}-u\right)}$, where $u$ is the agent's age. The choice of $D_{e}$ and the $\beta$ and $\delta$ parameters is explained in the parameterization section below

the economic ageing effect. Old age is postulated to be associated with a loss of skills and physical abilities which we model by taking the depreciation rate to be increasing in age $\left(\delta_{h}^{\prime}(t-v)>0\right)$. We assume that $\lim _{u \rightarrow D_{e}} \delta_{h}^{\prime}(s)=+\infty$ for $E<D_{e}<D_{b}$, i.e. the depreciation function features a vertical asymptote at $u=D_{e}$ which we call the age of economic death. ${ }^{6}$ Figure $1 \mathrm{~b}$ depicts the depreciation function we use in our quantitative analysis below.

By solving the differential equation for human capital subject to the initial condition we find:

$$
h(v, t)=e^{G(E)+\int_{v+E}^{t}\left[\gamma l(v, \tau)-\delta_{h}(\tau-v)\right] d \tau},
$$

and thus:

$$
\begin{aligned}
& \frac{\partial h(v, t)}{\partial l(v, \tau)}= \begin{cases}\gamma h(v, t) & \text { for } \tau<t \\
0 & \text { for } \tau \geq t\end{cases} \\
& \frac{\partial h(v, t)}{\partial E}=\left[G^{\prime}(E)-\left(\gamma l(v, v+E)-\delta_{h}(E)\right)\right] h(v, v+E)
\end{aligned}
$$

By its very nature, human capital is a predetermined variable in that it is only affected by choices made in the past. This explains why only past labour supply decisions influence the stock at any moment in time. Note furthermore that the proportional effect on the human capital stock of a marginally higher level of education is captured

Footnote 5 continued

Shaw (1989) and Imai and Keane (2004). The latter postulate a constant depreciation rate and an agedependent learning coefficient, $\gamma(s)$. Assuming that $\gamma(s)$ must be non-negative, their approach features less scope for ageing effects.

6 If economic and biological death were to coincide, then the agent's incentives to retire are severely weakened and withdrawal from the labour market takes place very late in life. In Heijdra and Reijnders (2015) we study an alternative economic ageing process which does not feature a vertical asymptote. 
by the difference between the gross return to education $\left(G^{\prime}(E)\right)$ and the net return to job market experience $\left(\gamma l(v, v+E)-\delta_{h}(E)\right)$.

The agent chooses the education level $E$, the retirement age $R$, and time profiles for consumption $\{c(v, \tau)\}_{\tau=v}^{v+D_{b}}$, and labour supply $\{l(v, \tau)\}_{\tau=v}^{v+D_{b}}$ in order to maximize lifetime utility (2a) subject to the lifetime budget constraint (2c) and the human capital equation (2e). The first-order condition for consumption during life is given by:

$$
\Phi_{c}(c(v, t), z(v, t))=\lambda(v) e^{-(r-\rho)(t-v)}, \quad \text { for } 0 \leq t-v \leq D_{b}
$$

where $\lambda(v)$ is the (optimized value of the) Lagrange multiplier for the lifetime budget constraint (2c) representing the marginal utility of wealth. At each moment in time, the agent chooses consumption such that the marginal utility cost (right-hand side of (3a)) is equated to the marginal benefit (left-hand side of (3a)) of additional consumption.

One feature of the optimal consumption path can be deduced already. Since the righthand side of ( $3 a$ ) is continuous in the consumer's age, it follows from the indivisibility of schooling time and the perfect divisibility of labour supply that there generally exists a discrete jump in consumption at age $E$ satisfying: ${ }^{7}$

$$
\frac{c(v, v+E)}{c\left(v, v+E^{-}\right)}=\left(\frac{1-e_{0}}{1-l(v, v+E)}\right)^{\frac{(1-\sigma) \varepsilon_{z}}{1-\varepsilon_{z}(1-\sigma)}}
$$

where we write $f\left(x^{-}\right)$for the left limit of $f$ at $x$, i.e. $f\left(x^{-}\right) \equiv \lim _{z} \nearrow x f(z)$. If, for example, the optimally chosen supply of hours at labour market entry exceeds the time requirement of schooling $\left(l(v, v+E)>e_{0}\right)$, then it follows from (3b) that consumption features an upward jump at age $E\left(c(v, v+E)>c\left(v, v+E^{-}\right)\right)$which compensates for the downward jump in leisure occurring at that point in the life cycle.

The first-order condition for labour supply during the work career is given by:

$$
\begin{aligned}
& \Phi_{z}(c(v, t), z(v, t))=[w(t) h(v, t)+\gamma V(v, t)] \lambda(v) e^{-(r-\rho)(t-v)}, \\
& \quad \text { for } E \leq t-v<R
\end{aligned}
$$

where $V(v, t)$ is the present value of future wage income:

$$
V(v, t) \equiv \int_{t}^{v+R} w(\tau) l(v, \tau) h(v, \tau) e^{-r(\tau-t)} d \tau .
$$

Again the optimal decision rule equates marginal costs and benefits of increasing leisure consumption. By working a little less the agent obtains more leisure, the marginal benefits of which are given by the left-hand side of (3c). The marginal cost of leisure is given by the right-hand side of (3c) and consists of forgone direct wage income $w(t) h(v, t)$ (backward-looking) plus the imputed value of forgone human capital $\gamma V(v, t)$ (forward-looking), all expressed in utility terms.

\footnotetext{
7 Heckman (1974) was the first to stress the importance of non-separable preferences in a life-cycle model with endogenous consumption and labour supply choices.
} 
The first-order condition for the years of schooling (and age of labour market entry) is given by:

$$
\begin{aligned}
& \Phi\left(c\left(v, v+E^{-}\right), 1-e_{0}\right)-\Phi(c(v, v+E), 1-l(v, v+E)) \\
& =\lambda(v) e^{-(r-\rho) E}[w(v+E) l(v, v+E) h(v, v+E) \\
& \left.\quad-\int_{v+E}^{v+R} w(t) l(v, t) \frac{\partial h(v, t)}{\partial E} e^{-r(t-v-E)} d t+\left(c\left(v, v+E^{-}\right)-c(v, v+E)\right)\right] .
\end{aligned}
$$

This optimality condition equalizes the marginal gains and losses from additional schooling. The left-hand side represents the change in felicity that occurs the moment the agent leaves school and enters the labour market. The right-hand side states the three components that make up the marginal utility cost of increasing $E$. The first term in square brackets shows that the agent foregoes wage earnings by staying in school a bit longer. The second term is a negative cost, namely the net return to education relative to gaining experience on the job. The third term gives the effect of the consumption jump at age $E$.

Finally, the first-order condition for the optimal retirement age is given by:

$$
\begin{aligned}
& \Phi\left(c\left(v, v+R^{-}\right), 1-l\left(v, v+R^{-}\right)\right)-\Phi(c(v, v+R), 1-l(v, v+R)) \\
& =\lambda(v) e^{-(r-\rho) R}\left[-w\left(v+R^{-}\right) l\left(v, v+R^{-}\right) l\left(v, v+R^{-}\right)\right. \\
& \left.\quad+\left(c\left(v, v+R^{-}\right)-c(v, v+R)\right)\right]
\end{aligned}
$$

The left-hand side gives the change in felicity experienced at labour market exit. The right-hand represents the utility cost of retiring slightly later on in life. The first term in square brackets is a negative cost consisting of the wage income that is earned by staying in the work force somewhat longer. The second term accounts for a possible consumption jump at age $R$. It follows from (3a) that:

$$
\frac{c(v, v+R)}{c\left(v, v+R^{-}\right)}=\left(\frac{1-l\left(v, v+R^{-}\right)}{1-l(v, v+R)}\right)^{\frac{(1-\sigma) \varepsilon_{z}}{1-\varepsilon_{z}(1-\sigma)}} .
$$

Because labour is perfectly divisible and labour supply is zero at retirement $(l(v, v+R)=0)$, it follows that the consumption path is continuous at age $R$ and that $l\left(v, v+R^{-}\right)=0$, i.e. there is no jump in labour supply at retirement either.

We summarize the key microeconomic relationships in panel (a) of Table 2 . The micro model is written entirely in the agent's age $u \equiv t-v$. Scaled variables are defined as:

$$
\tilde{c}(u) \equiv \frac{c(v, v+u)}{Z(v)}, \quad \tilde{V}(u) \equiv \frac{V(v, v+u)}{Z(v)}, \quad \mu \equiv \frac{1}{Z(v)}\left(\frac{\varepsilon_{c}}{\lambda(v)}\right)^{\sigma^{*}},
$$


Table 2 Model equations

(a) Microeconomic relationships

$$
\begin{aligned}
& \tilde{c}(u)=\mu z(u)^{\sigma^{*} \varepsilon_{z}(1-1 / \sigma)} e^{\sigma^{*}(r-\rho) u}, \quad 0 \leq u \leq D_{b} \\
& l(u)=1-\frac{\varepsilon_{z}}{1-\varepsilon_{z}} \frac{\tilde{c}(u)}{\tilde{w} e^{g u} h(u)+\gamma \tilde{V}(u)}, \quad E \leq u<R \\
& z(u) \equiv \begin{cases}1-e_{0} & \text { for } 0 \leq u<E \\
1-l(u) & \text { for } E \leq u<R \\
1 & \text { for } R \leq u \leq D_{b}\end{cases} \\
& h(u)=e^{G(E)} e^{\int_{E}^{u}\left[\gamma l(s)-\delta_{h}(s)\right] d s}, \quad E \leq u<D_{e} \\
& \tilde{V}(u)=\tilde{w} e^{g u} \int_{u}^{R} l(s) h(s) e^{-(r-g)(s-u)} d s, \quad E \leq u<R \\
& e^{-r E} \tilde{V}(E)=\int_{0}^{D_{b}} \tilde{c}(u) e^{-r u} d u \\
& \tilde{w} e^{g E} l(E) h(E)=\frac{\tilde{c}(E)}{\sigma^{*}\left(1-\varepsilon_{z}\right)} \frac{\left(\frac{1-e_{0}}{1-l(E)}\right)^{\sigma^{*} \varepsilon_{z}(1-1 / \sigma)}-1}{1-1 / \sigma} \\
& +\left[G^{\prime}(E)-\gamma l(E)+\delta_{h}(E)\right] \tilde{V}(E)
\end{aligned}
$$

(b) Macroeconomic relationships

$$
\begin{aligned}
& c=\frac{1}{\Delta\left(n, D_{b}\right)} \int_{0}^{D_{b}} \tilde{c}(u) e^{-(n+g) u} d u \\
& h c \equiv \frac{1}{\Delta\left(n, D_{b}\right)} \int_{E}^{R} l(u) h(u) e^{-n u} d u \\
& c=(r-g-n) k+\tilde{w} h c \\
& \tilde{w}=\left(1-\varepsilon_{k}\right) \Omega_{0}\left(\frac{k}{h c}\right)^{\varepsilon_{k}} \\
& r+\delta_{k}=\varepsilon_{k} \Omega_{0}\left(\frac{k}{h c}\right)^{-\left(1-\varepsilon_{k}\right)}
\end{aligned}
$$

(c) Demographic steady state

$1=b \Delta(n, B)$

The properties of $\Delta\left(n, D_{b}\right)$ and $\Delta(n, B)$ are covered in Lemma 3. Redefined variables: $\tilde{c}(u) \equiv$ $c(v, t) / Z(v), \tilde{V}(u) \equiv V(v, t) / Z(v), z(u) \equiv z(v, v+u), l(u) \equiv l(v, v+u), h(u) \equiv h(v, v+u)$, and $\mu \equiv Z(v)^{-1}\left(\left(1-\varepsilon_{z}\right) / \lambda(v)\right)^{\sigma^{*}}$. Auxiliary parameter: $\sigma^{*} \equiv \frac{\sigma}{1-\varepsilon_{z}(1-\sigma)}$

and with a slight abuse of notation we write:

$$
l(u) \equiv l(v, v+u), \quad h(u) \equiv h(v, v+u), \quad z(u) \equiv c(v, v+u) .
$$

By virtue of the structure of the felicity function, the microeconomic relationships provide time-invariant solutions for the life-cycle dates $E$ and $R$, and age-dependent solutions for scaled consumption, $\tilde{c}(u)$, the scaled value of the stock of human capital, $\tilde{V}(u)$, labour supply, $l(u)$, and the stock of human capital, $h(u)$.

Equation (T1.1) expresses the optimal path for consumption over the life cycle conditional on a time-invariant term involving the transformed marginal utility of wealth $(\mu)$, the amount of leisure consumption $(z(u))$, and an exponential term $\left(e^{\sigma^{*}(r-\rho) u}\right)$. It is obtained by using (2b) and (3a). Equation (T1.2) gives the expression for optimal labour supply over the life cycle. It is obtained by combining (3a) and (3c), using (2b), and noting that $w(t)=w(v) e^{g(t-v)}$ and $w(t)=\tilde{w} Z(t)$. Equations (T1.3)-(T1.6) are 
rewritten versions of, respectively, (2d), (2e), (3d), and (2c). Finally, equation (T1.7) gives the implicit function determining the optimal amount of schooling. It is obtained by substituting (3a)-(3b) and the expression for $\partial h(v, t) / \partial E$ in (3e) and rewriting.

\subsection{Demography and Macroeconomic Equilibrium}

We allow for a positive growth rate of the population, which we denote by $n$, and assume that the economy is in a demographic steady state. Agents are fertile for ages $0 \leq u<B<D_{b}$ and the net birth rate $b$ is age-independent. The population level at time $t$ is $P(t)=P(v) e^{n(t-v)}$ and the size of the new cohort born at time $v$ is given by $P(v, v)=b \int_{v-B}^{v} P(s, v) d s$. Since $P(s, v)=P(v, v)$ for $0 \leq v-s \leq D_{b}$ and $P(t) \equiv \int_{t-D_{b}}^{t} P(v, v) d v$ it follows that:

$$
1=b \Delta(n, B)
$$

where $\Delta(\cdot)$ is a " demographic" function implied by the postulated birth and mortality processes. ${ }^{8}$ In general form this function is given by:

$$
\Delta(n, T) \equiv \begin{cases}\frac{1-e^{-n T}}{n} & \text { for } n \neq 0 \\ T & \text { for } n=0\end{cases}
$$

where $T$ is a positive parameter. We show in Lemma 3 in the "Appendix 2" that $\Delta(n, T)$ is strictly positive, decreasing in $n$, and increasing in $T$.

Equation (4a) is the demographic equilibrium condition providing an implicit relationship between the net birth rate $b$, the growth rate of the population $n$, and the maximum age of fertility $B$. Once two of these parameters have been set, the third is implied by (4a). In Fig. 2, the solid line depicts $\Delta(n, B)$. By selecting a particular value for the net birth rate, say $b=b_{0}$, the equilibrium population growth rate $n_{0}$ is obtained. For future reference we restate the demographic steady-state condition in (T1.13) in Table 2.

The age composition of the population is derived as follows. Absolute cohort sizes satisfy $P(v, t)=P(v, v)$ for $v \leq t \leq v+D_{b}$ and $P(v, t)=0$ for $t>v+D_{b}$ and $P(t, t)=P(v, v) e^{n(t-v)}$ we easily find that relative cohort sizes in the age domain are given by:

$$
p(v, v+u) \equiv \begin{cases}\frac{e^{-n u}}{\Delta\left(n, D_{b}\right)} & \text { for } 0 \leq u \leq D_{b} \\ 0 & \text { for } u>D_{b}\end{cases}
$$

where $\bar{b} \equiv P(t, t) / P(t)=1 / \Delta\left(n, D_{b}\right)$ represents the crude birth rate. In Fig. 2 the equilibrium crude birth rate associated with the net rate $b_{0}$ is given by $\bar{b}_{0}$. The relative size of a cohort falls with its age not because of ongoing mortality but rather because the population as a whole is growing over time.

8 As we model a closed economy, immigration and emigration flows are absent by definition. 
Fig. 2 Demographic equilibrium. The solid line depicts $(b, n)$ combinations for which the demographic equilibrium condition is satisfied (holding constant $B$ ). For a given net birth rate, $b_{0}$, the equilibrium growth rate of population growth is $n_{0}$, i.e. $1 / b_{0}=\Delta\left(n_{0}, B\right)$. The dashed line plots the inverse of the crude birth rate as a function of $n$, e.g. $1 / \bar{b}_{0}=\Delta\left(n_{0}, D_{b}\right)$

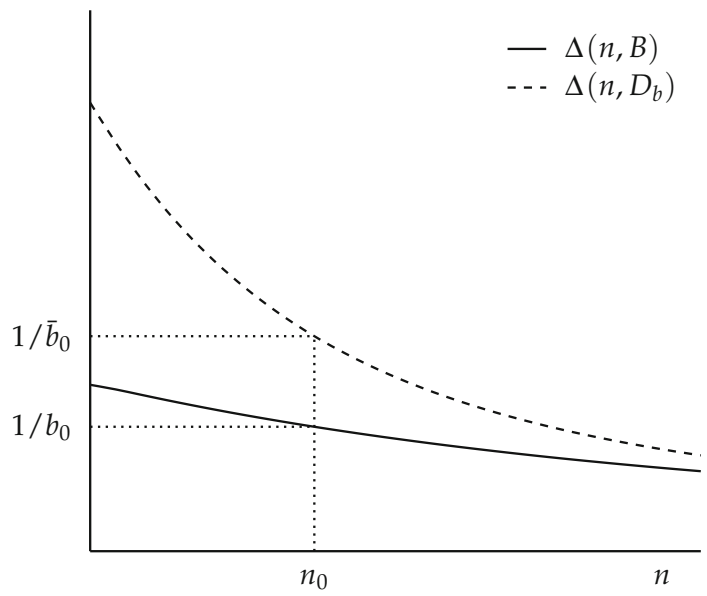

Armed with the relative cohort weights (4c) it is possible to derive the key macroeconomic relationships—-see equations (T1.8)-(T1.12) in Table 2. Equation (T1.8) is obtained as follows. First, note that total consumption is defined as $C(t) \equiv$ $P(t) \int_{t-D_{b}}^{t} c(v, t) p(v, t) d v$, where we have used the fact that $P(v, t) \equiv P(t) p(v, t)$. By exploiting the stationarity property of scaled consumption, $\tilde{c}(t-v)$, and substituting the balanced growth path for productivity, $Z(t)=Z(v) e^{g(t-v)}$, as well as (4a)-(4c) we obtain:

$$
c(t) \equiv \frac{C(t)}{P(t) Z(t)}=\frac{1}{\Delta\left(n, D_{b}\right)} \int_{0}^{D_{b}} \tilde{c}(s) e^{-(n+g) s} d s,
$$

where $c(t)$ denotes consumption in terms of raw efficiency units. Since the righthand side of $(4 \mathrm{~d})$ is independent of the generations index $v$, it follows that $c(t)$ is time-invariant, as is indicated in (T1.8).

Equation (T1.9) is obtained by noting that $H C(t) \equiv P(t) \int_{t-R}^{t-E} l(v, t) h(v, t)$ $p(v, t) d v$ and recalling that $l(v, t), h(v, t)$, and $p(v, t)$ depend only on age. Finally, equation (T1.10) follows in a straightforward fashion from the aggregate asset accumulation equation,

$$
\dot{A}(t)=r A(t)+w(t) H C(t)-C(t)
$$

in combination with the capital market equilibrium condition $A(t)=K(t)$, where $A(t) \equiv P(t) \int_{t-D_{b}}^{t} a(v, t) p(v, t) d v$, and the steady-state condition $\dot{k}(t) / k(t)=$ $\dot{K}(t) / K(t)-(g+n)=0$.

The model features a two-way interaction between the microeconomic and macroeconomic parts. For given values of the macroeconomic equilibrium factor prices $(\tilde{w}$ and $r$ ), the microeconomic part determines optimal values for $\tilde{c}(u), \tilde{V}(u), l(u), h(u), E$, and $R$. Using these micro variables in the macroeconomic part gives general equilibrium solutions for $c, h c, k, \tilde{w}$, and $r$. The functional form of the felicity function (2b) satisfies the King-Plosser-Rebelo conditions ensuring that 
income and substitution effects on labour supply of changes in $\tilde{w}$ exactly cancel out (King et al. 2002). In the context of the model studied here, it thus follows that (a) the optimal choices for $E, R, l(u)$, and $h(u)$ are independent of the rental rate on human capital, $\tilde{w}$, and (b) that optimal choices for $\tilde{c}(u)$ and $\tilde{V}(u)$ are homogeneous of degree one in $\tilde{w}$.

\subsection{Model Solution and Parameterization}

As we cannot obtain an analytical solution to the system of equations given in Table 2 we have to solve it numerically. The main difficulty lies in the fact that labour supply at any point in time depends both on past (via human capital) and future (through experience effects) labour supply choices. This means that we have to loop over the age profile for labour supply in order to obtain a consistent solution. At the same time, the non-separability of leisure and consumption in the felicity function means that we cannot solve for labour supply choices separate from consumption allocations. To speed up the computations we program the model in Fortran 90 and use spline interpolation and root finding techniques.

In view of the highly stylized nature of the model we stop short of a full calibration exercise. ${ }^{9}$ Instead we focus on a small number of stylized facts concerning labour supply, wages, and the retirement age and choose the structural parameters to match these. We check the quality of the parameterization by showing that empirically reasonable values are obtained for key indicators such as the age-dependent labour supply elasticities (see below).

The structural parameters of the model are given in Table 3. The model is parameterized in the following way. In the base model we assume that individuals live for 78 years $\left(D_{b}=60\right)$ and that the population grows at $1 \%$ per annum $(n=0.01)$. For these values, the crude birth rate is just over $2 \%$ per annum $\left(\bar{b}=2.2164 \times 10^{-2}\right)$. If the maximum age of fertility is set at the biological age of forty $(B=22)$ this value for the crude birth rate is obtained if the net birth rate is set at $b=5.0638 \times 10^{-2}$. We parameterize the model in such a way that the individual chooses 4 years of schoolingthus entering the labour market at age $22(E=4)$-and retires at biological age 65 $(R=47)$. We furthermore ensure that the equilibrium interest rate is $5 \%$ per annum $(r=0.05)$ and that per capita output is normalized to unity $(y=1)$. The depreciation rate for physical capital and the exogenous rate of economic growth are set at, respectively, 7 and $2 \%$ per annum $\left(\delta_{k}=0.07\right.$ and $\left.g=0.02\right)$. For the intertemporal substitution elasticity we use $\sigma=0.7$, a value that is consistent with the empirical evidence (e.g. Skinner 1985; Attanasio and Weber 1995). The pure rate of time preference is set at $\rho=0.025$, thus ensuring a strong savings motive in the population. The individual uses half of the time endowment for studying during the schooling period $\left(e_{0}=0.5\right)$. Interpreting the net-of-sleeping day to last for 16 hours, this means that each student spends 8 hours per day on formal education. For future reference, we define a full-time working day as $l_{F}=0.5$.

\footnotetext{
9 In Heijdra and Reijnders (2015) we formulate and calibrate a version of the model with the following more realistic features: (a) indivisible labour (as in Sect. 4.2 below), (b) two imperfectly substitutable labour types (skilled and unskilled), (c) a rudimentary pension system, and (d) a realistic mortality profile.
} 
Table 3 Parameter values

\begin{tabular}{lll}
\hline Targeted steady-state life-cycle dates & \\
$E$ & 4.0000 & Years of education \\
$R$ & 47.0000 & Retirement age \\
Targeted steady-state macro outcomes & \\
$y$ & 1.0000 & Steady-state output \\
$r$ & 0.0500 & Interest rate \\
Chosen parameters & & \\
$D_{e}$ & 54.0000 & Maximum feasible retirement age \\
$D_{b}$ & 60.0000 & Age at certain death \\
$\sigma$ & 0.7000 & Intertemporal substitution elasticity \\
$\rho$ & 0.0250 & Pure rate of time preference \\
$\gamma$ & 0.0800 & Return to experience \\
$\delta_{0}$ & $0.7654 \times 10^{-2}$ & Parameter of the human capital depreciation profile \\
$\delta_{1}$ & 1.5000 & Parameter of the human capital depreciation profile \\
$\beta_{1}$ & 0.1000 & Parameter of the return-to-education function \\
$e_{0}$ & 0.5000 & Time spent studying during education \\
$n$ & 0.0100 & Population growth rate \\
$g$ & 0.0200 & Economic growth rate \\
$\delta_{k}$ & 0.0700 & Depreciation rate of physical capital \\
Calibrated parameters & \\
$\varepsilon_{c}$ & 0.3198 & Preference parameter for consumption \\
$\beta_{0}$ & -0.3046 & Parameter of the return-to-education function \\
$\beta_{2}$ & $0.5960 \times 10^{-2}$ & Parameter of the return-to-education function \\
$\bar{b}$ & $2.2164 \times 10^{-2}$ & Crude birth rate \\
$\varepsilon_{k}$ & 0.2351 & Capital efficiency parameter \\
$\Omega_{0}$ & 1.5610 & Scale factor production function \\
\hline & & \\
\hline & & \\
\hline & &
\end{tabular}

The return to education is governed by a simple quadratic function:

$$
G(E)=\beta_{0}+\beta_{1} E-\beta_{2} E^{2}, \quad \beta_{1}>0, \quad \beta_{2}>0 .
$$

We choose the $\beta$-parameters to ensure that $e^{G(E)}$ is increasing and concave in $E$ for a range of plausible values. We fix $\beta_{1}=0.10$, set $\beta_{2}$ in such a way that the first-order condition for schooling [given in (T1.7)] is satisfied for $E=4$, and choose the value for $\beta_{0}$ such that $G(4)=0$. This approach yields the concave training function that is illustrated in Fig. 1a.

Regarding the depreciation rate of human capital we propose:

$$
\delta_{h}(u)=\delta_{0}+\frac{1}{\delta_{1}\left(D_{e}-u\right)} \quad \text { for } 0 \leq u<D_{e}, \quad \delta_{0}>0, \quad \delta_{1}>0
$$


This function has a vertical asymptote at (what we call) the age of economic death, $D_{e}$. This means that the human capital stock is driven to zero at this age. ${ }^{10}$ The functional form allows us to easily control both the level and the shape of the depreciation profile. We choose $\delta_{0}$ and $\delta_{1}$ so that $\delta_{h}(u)$ remains nearly flat initially but increases rapidly when approaching $D_{e}$. This curvature guarantees an interior solution for the retirement age $R$. In particular, it will always lie to the left of $D_{e}$. In the base model we set $D_{e}=54$ which, in combination with a suitable choice for $\varepsilon_{z}$, gives rise to a calibrated equilibrium featuring retirement at age $65(R=47)$. The resulting depreciation function is depicted in Fig. 1b.

The hourly wage rate of a $u$-year old agent with education level $E$ is given by $W(u)=w(v+u) h(u)$. In logarithmic form we obtain:

$\ln W(u)=\ln w(v+u)+\beta_{0}+\beta_{1} E-\beta_{2} E^{2}+\gamma \int_{E}^{u} l(s) d s-\int_{E}^{u}\left[\delta_{0}+\frac{1}{\delta_{1}\left(D_{e}-s\right)}\right] d s$.

This expression bears a strong resemblance to a Mincer equation which typically regresses the log of wages on a constant, education, and potential experience (both in level and squared). Our specification is quadratic in education, consistent with the empirical findings by Heckman et al. (2006, p. 320) rejecting linearity. The estimates for $\beta_{1}$ reported by Heckman et al. range for white male workers between 0.10 and 0.13 (2006, p. 326). The parameter $\gamma$ is much harder to pin down from the empirical evidence because potential experience, as proxied by $u-E$, enters the theoretical Mincer equation in a very complicated fashion-indeed, $u$ and $E$ enter non-additively in our expression. Whereas in empirical studies experience-squared is included to capture the concavity of the age-earnings profile in the data, in our model the depreciation rate of human capital captures that phenomenon. After some experimentation we choose $\gamma=0.08$, which implies that a full-time worker enjoys wage growth due to experience of $4 \%$ per annum $\left(=\gamma l_{F}=0.04\right)$. The implicit rate of return to education from the perspective of age $E$ is given by $r_{E} \equiv r+G^{\prime}(E)-\gamma l(E)+\delta_{h}(E)$ which is about $8.05 \%$ for the parameterization adopted here. ${ }^{11}$

We visualize the individual life-cycle profiles for the most important variables in Fig. 3. To facilitate interpretation, biological age $u+18$ rather than economic age $u \equiv t-v$ is plotted along the horizontal axes. Panel (a) depicts the calibrated life-

10 Pfeiffer and Reuss (2008, p. 633) use a special case of this function by setting $\delta_{0}=0$ and $D_{e}=D_{b}$. Hence, they do not make a distinction between economic and biological death. See also footnote 6 above.

11 Equation (T1.5) can be evaluated for $u=E$ to give:

$$
\tilde{V}(E)=\tilde{w} \int_{E}^{R} e^{g u} l(u) h(u) e^{-r(u-E)} d u .
$$

We interpret $\tilde{V}(E)$ as the underlying " asset" and derive its implicit rate of return by noting that it satisfies the following arbitrage equation:

$$
r_{E}=\frac{\tilde{w} e^{g E} h(E) l(E)+\frac{\partial \tilde{V}(E)}{\partial E}}{\tilde{V}(E)}
$$

where the path for $l(u)$ and the retirement age $R$ are held constant in the perturbation of $\tilde{V}(E)$. 

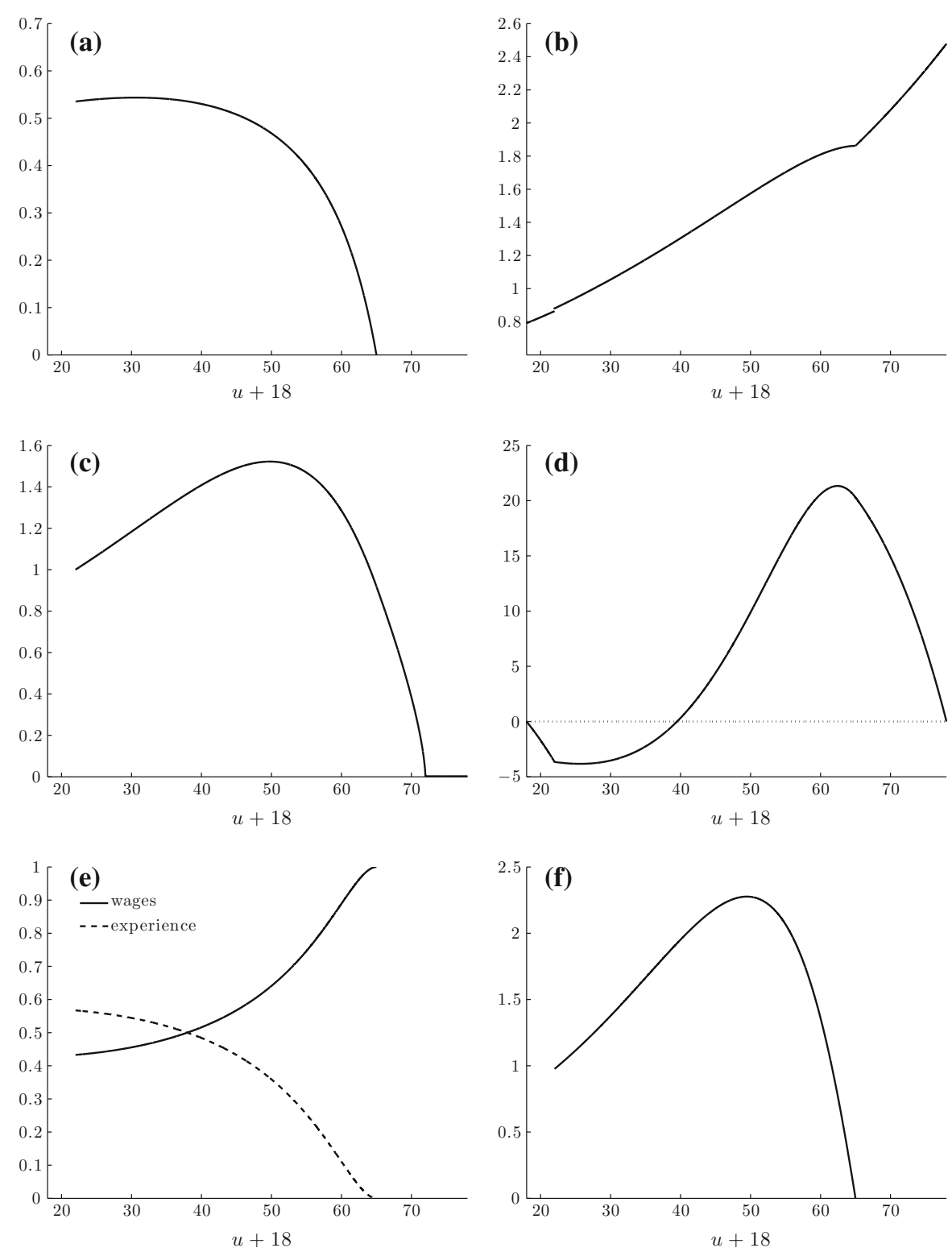

Fig. 3 Life-cycle profiles. a Labour supply, $l(u)$. b Scaled consumption, $\tilde{c}(u)$. c Human capital, $h(u)$. d scaled financial assets, $\tilde{a}(u)$. e Opportunity cost of leisure shares. f Wage income, $\tilde{w} e^{g u} l(u) h(u)$

cycle profile of labour supply. Labour market entry occurs at age 22 whilst retirement takes place at age 65. Labour supply is fairly constant for much of the work period but after age 60 the agent quickly reduces working hours and retires.

Panel (b) depicts the life-cycle path for scaled consumption. During the schooling and retirement periods leisure is constant and it follows from (T1.1) that consumption grows at an exponential rate $\sigma^{*}(r-\rho)$ which is about $2.2 \%$ per annum in the para- 
meterization (see Table 2). During the employment period the time change in leisure augments the growth rate of consumption somewhat. Consistent with (3b) there is a (small) upward jump in consumption at labour market entry.

Panel (c) illustrates the optimal life-cycle path of human capital. The parameterization procedure ensures that the stock of human capital at labour market entry equals unity. During much of working life experience effects are strong and depreciation is low, resulting in a sharply increasing profile for human capital. The peak is reached around the age of 53 after which economic ageing in the form of increasing depreciation starts to dominate resulting in the depletion of the stock at the calibrated age of 72 . Of course, as panel (a) shows, the agent has long since left the labour force at that age.

Panel (d) depicts the other stock that an individual accumulates over the life cycle, namely financial assets. Note that the asset path supporting (and originating from) an individual's optimal choices can be written as follows:

$$
\tilde{a}(u) \equiv \frac{a(v, v+u)}{Z(v)}=\int_{0}^{u}\left[\tilde{w} e^{g s} l(s) h(s)-\tilde{c}(s)\right] e^{r(u-s)} d s .
$$

As the diagram shows, assets are zero at the beginning and end of life and the agent is a net debtor until about age 40. Assets peak just before withdrawing from the labour market and are gradually decumulated during the retirement phase.

Panel (e) depicts the changing role of explicit and implicit remuneration of labour over the life cycle-a phenomenon first noted by Imai and Keane (2004, p. 602). A young individual is willing to work for relatively low wages because a large part of the work remuneration accrues in the form of experience effects. The opposite holds for an old individual, who has little use for building up experience due to the brief remaining lifetime and instead is affected principally by wages in the labour supply decision. In order to get a quantitative " feel" for the importance of the age effect in labour supply we follow Keane and Rogerson (2012, pp. 469-471) by computing the income-compensated age-dependent labour supply elasticities implied by our parameterization. The resulting elasticities are visualized in Fig. 4. The solid line represents

Fig. 4 Labour supply elasticities. The solid line depicts the temporary labour supply elasticity, i.e. the percentage rate of decline in labour supply of a $u$-year old worker resulting from a $1 \%$ increase in the labour income tax that lasts for one year. The dashed line depicts the labour supply elasticity for a permanent tax increase. In both cases the tax revenue is rebated to the agent in the form of a lump-sum transfer

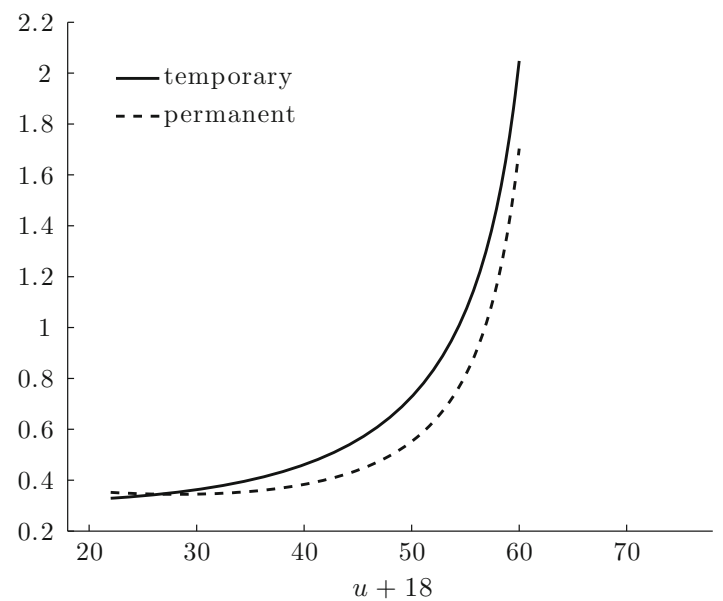


the percentage rate of decline in labour supply of a $u$-year old worker resulting from a 1-year increase in the labour income tax, the revenue of which is rebated to the agent in the form of a lump-sum transfer. Whereas this transitory labour elasticity is quite low for young workers, it is strongly increasing in age and is rather large for old workers. A similar pattern is observed for the compensated elasticity with respect to a permanent tax increase (the dashed line). Interestingly, the results from our model are very similar to the ones reported by Keane and Rogerson (2012, p. 471) which themselves are based on the estimated model by Imai and Keane (2004).

Key features of the general equilibrium attained in the base model (BM hereafter) are presented in column (a) of Table 4 . The consumption-output ratio is $79.1 \%$, and the capital-output ratio is 1.960 . Both are quite plausible values.

\section{Demographic Shocks}

In this section we study the quantitative effects of stylized demographic ageing shocks on microeconomic behaviour and macroeconomic outcomes. We restrict attention to three types of demographic shocks. The first shock is a biological longevity boost (BLB hereafter), consisting of a substantial increase in the length of life accompanied by a constant population growth rate and an unchanged human capital depreciation schedule. The second shock combines economic and biological ageing and is called a comprehensive longevity boost (CLB hereafter). This case combines the BLB with an increase in economic longevity which we model as an outward shift of the depreciation schedule for human capital. Finally, the third shock is a pure baby bust (BB hereafter) scenario, in which the net birth falls but the length of biological and economic life both remain unchanged.

\subsection{Biological Longevity Boost}

A biological longevity boost (BLB) consists of an exogenous increase in $D_{b}$. Holding constant the fertility parameters $(b$ and $B)$ and thus the population growth rate $n$, it follows from Proposition 1(i) that the crude birth rate $\bar{b}$ falls and the old-age dependency ratio of the population increases. The latter variable is a simple indicator for the age structure of the population. It represents the ratio of old to young people:

$$
d r \equiv \frac{\int_{u_{\mathrm{old}}}^{D_{b}} p(v, v+u) d u}{\int_{0}^{u_{\mathrm{old}}} p(v, v+u) d u},
$$

where somebody above biological age 65 is considered to be old $\left(u_{\text {old }}=47\right)$. In the base model we find that $d r=0.2032$. In Fig. 5a the longevity boost rotates the $\Delta\left(n, D_{b}\right)$ line in a clockwise fashion and the implied crude birth rate falls. Figure $5 \mathrm{c}$ illustrates how the longevity shock affects the composition of the population. In that figure, the thick solid line represents the base case scenario (BM). The dashed line shows how the population half-pyramid changes as a result of a 7.8 year increase in the length of life from $D_{b}=60$ to $D_{b}=67.8$. The population ages because mass of the 


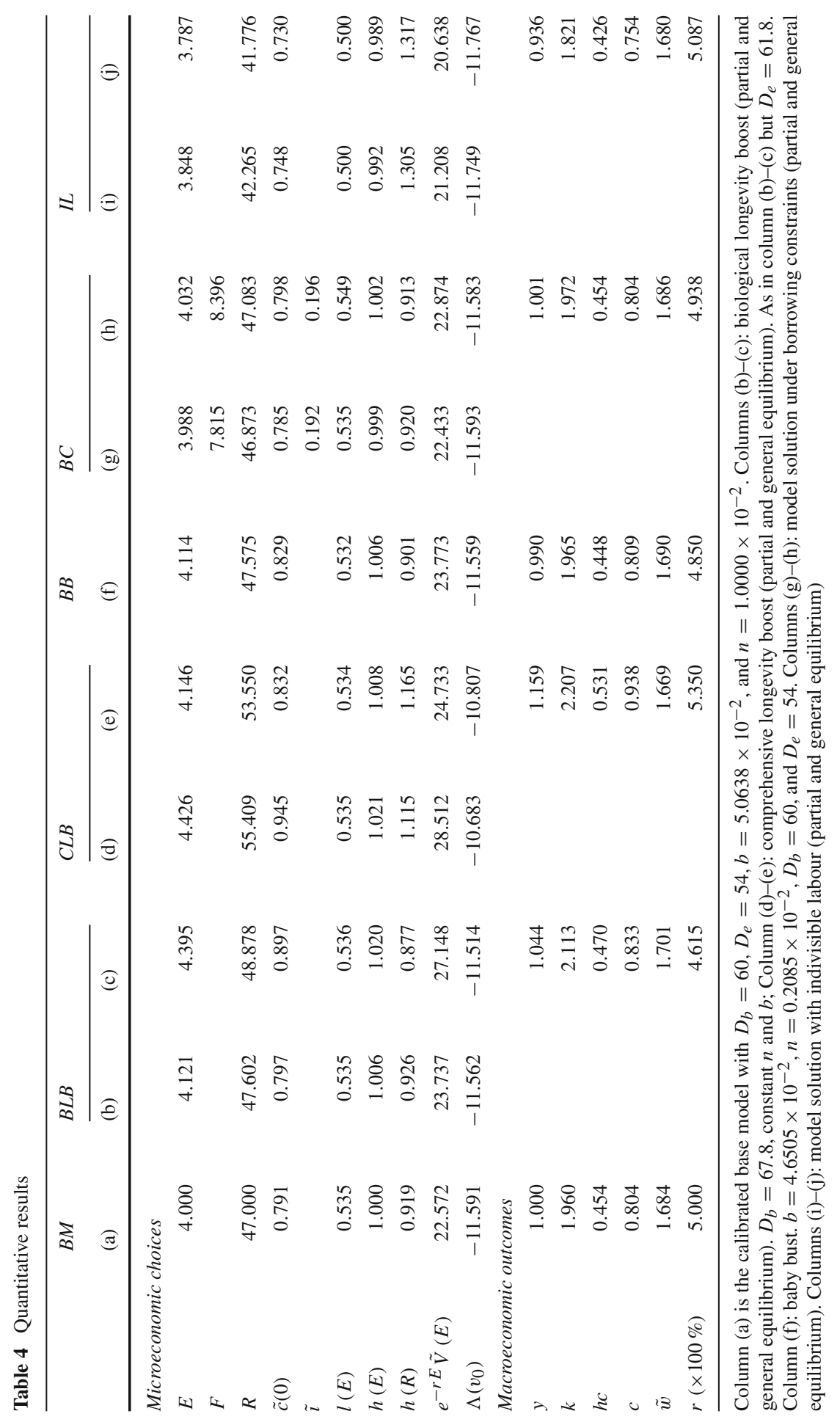




\section{(A) Longevity Boost}
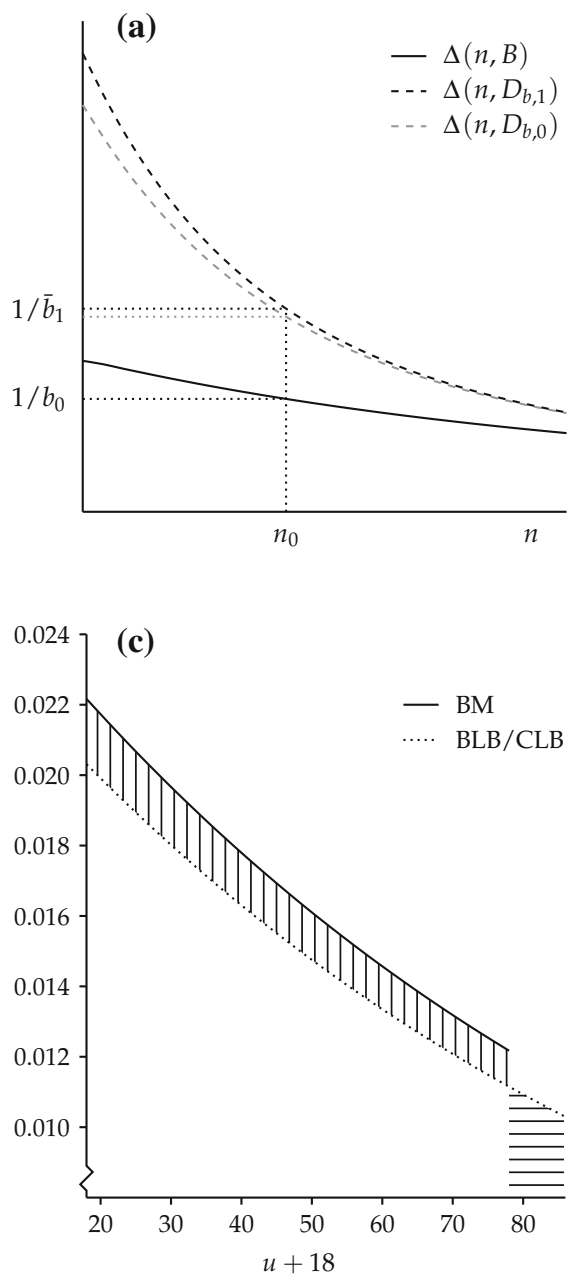

(B) Baby Bust
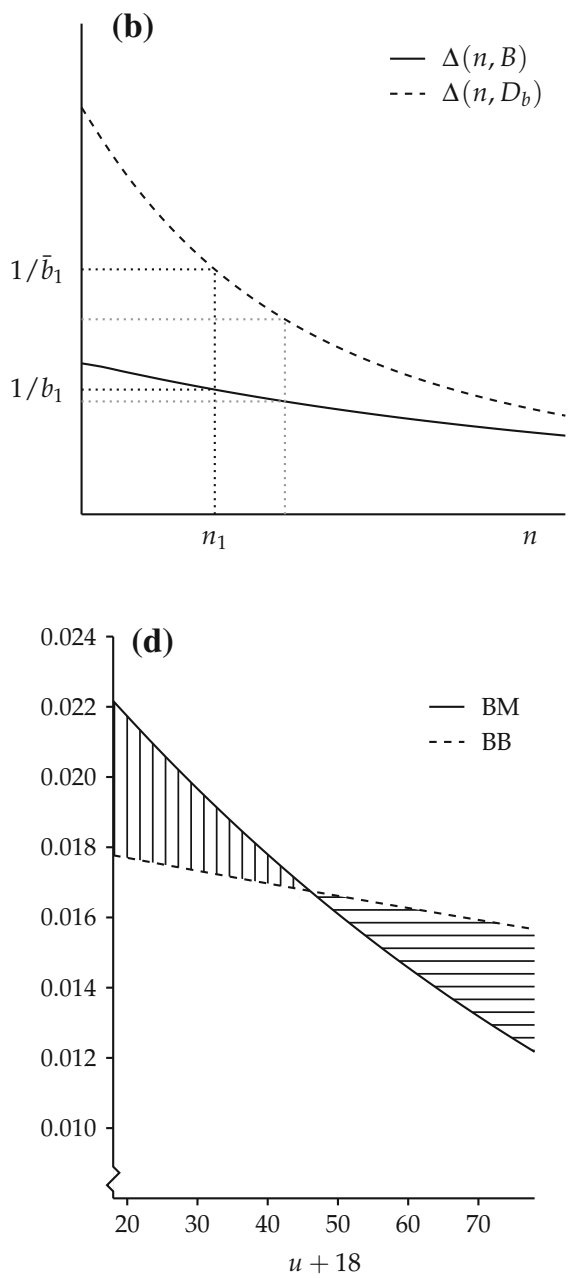

Fig. 5 Demographic shocks. A Longevity boost: a demographic equilibrium, c relative cohort size. B Baby bust: $\mathbf{b}$ demographic equilibrium, $\mathbf{d}$ relative cohort size

distribution is shifted from the young to the old. In the new demographic equilibrium $\bar{b}=2.0310 \times 10^{-2}$ and $d r=0.3130$.

Blessed with a longer lifetime, individuals will make different choices than in the base case scenario, even if we hold factor prices constant at their pre-shock levels. In column (b) of Table 4 we present the partial equilibrium effects of the longevity boost. Schooling and the retirement age increase by, respectively, 0.12 and 0.60 years, whilst the working career $(R-E)$ is extended by almost half of 1 year. In view of the fact that life is extended by 7.8 years, these effects are modest indeed. Much of the extra 
years of life will be enjoyed in the form of leisure, i.e. the retirement period $\left(D_{b}-R\right)$ increases by more than 7 years.

But this is not the end of the story because the adjustments of individual plans result in significant changes in factor supplies and thus in equilibrium factor prices. The general equilibrium effects of the longevity boost are reported in column (c) of Table 4 . The stocks of physical and human capital increase by, respectively, 7.85 and $3.35 \%$ resulting in an increase in output of $4.39 \%$, a 39 basis point drop in the interest rate, and a $1.01 \%$ increase in the rental rate on human capital. The general equilibrium effects on $E, R$, and $R-E$ are in the same direction but significantly larger than their partial equilibrium counterparts. For future reference we summarize the general equilibrium effects on the key variables in column (a) of Table 5.

The intuition behind the effects on factor prices is as follows. Even though the length of an individual's biological life increases dramatically, the duration of economic life is unaffected because the human capital depreciation schedule is held constant by assumption under the BLB scenario. Agents have very little incentive to enjoy more schooling and to retire later (compared to the $\mathrm{BM}$ ) because economic ageing still sets in at exactly the same phase of life. As a result, the stock of human capital increases only slightly. The increased length of biological life, however, necessitates higher savings resulting in a substantial increase in the stock of physical capital. Human capital thus becomes relatively scarce under the BLB leading to an increase in its rental rate and an decrease in the rate of interest.

\subsection{Comprehensive Longevity Boost}

A comprehensive longevity boost (CLB) features exogenous increases in both $D_{b}$ and $D_{e}$, i.e. the biological and economic lifespan are both increased under this shock. The biological shock is parameterized in the same way as before; $D_{b}$ increases from $D_{b}=60$ to $D_{b}=67.8$, and the population ages as is illustrated by the dashed line in Fig. 5c. The increase in economic longevity consists of an increase in the age of economic death from $D_{e}=54$ to $D_{e}=61.8$. In terms of Fig. $1 \mathrm{~b}$ the human capital depreciation function shifts to the right.

In column (d) of Table 4 we present the partial equilibrium effects of the CLB. Schooling and the retirement age increase by, respectively, 0.43 and 8.41 years, the working career $(R-E)$ is extended by almost 8 years, and the retirement period $\left(D_{b}-R\right)$ is reduced by more than half of 1 year.

The general equilibrium effects of the CLB are reported in column (e) of Table 4 and summarized in column (d) of Table 5. The stocks of physical and human capital increase by, respectively, 12.63 and $16.95 \%$ resulting in an increase in output of $15.92 \%$, a 35 basis point increase in the interest rate, and a $0.88 \%$ decrease in the rental rate on human capital. Interestingly, the general equilibrium effects on $E, R$, and $R-E$ are in the same direction but significantly smaller than their partial equilibrium counterparts. In contrast, the change in the retirement period is in the opposite direction.

The intuition behind the effects on factor prices is as follows. Both biological and economic life spans are increased. The former gives rise to increased saving and a boost to the stock of physical capital. The latter stimulates the accumulation of human capital 
and slows down its rate of depreciation during the active period. Since the working career increases, the economy-wide stock of human capital increases substantially. Human capital thus becomes relatively abundant under the CLB leading to a decrease in its rental rate and an increase in the rate of interest.

As the comparison between columns (c) and (e) of Table 4 reveals, factor price changes under the CLB are in the opposite direction to those resulting from the BLB. This result confirms the findings of Heijdra and Reijnders (2015) who study longevity shocks in a more thoroughly calibrated model with age-dependent human capital depreciation. Whether real life changes in longevity are closer to BLB or CLB remains an open question in the absence of convincing data on changes in labour productivity at older ages.

\subsection{Baby Bust}

A baby bust (BB) consists of a decrease in the net birth rate $b$. For a given age of death $D_{b}$, it follows from Proposition 1 (ii) that the population growth rate $n$ and crude birth rate $\bar{b}$ both decline whilst the dependency ratio of the population increases. Figure $5 \mathrm{~b}$ illustrates how the demographic equilibrium changes as a result of a drop in the net birth rate. In Fig. 5d the dashed line illustrates how the composition of the population changes compared to the base case scenario if the net birth rate decreases from $b=5.0638 \times 10^{-2}$ to $b=4.6505 \times 10^{-2}$ (where the numbers have been chosen to produce a $20 \%$ drop in the crude birth rate). Again, as in the previous ageing shock, mass of the distribution is shifted from young to old agents. In the new demographic equilibrium $n=0.2085 \times 10^{-2}, \bar{b}=1.7731 \times 10^{-2}$, and $d r=0.2597$.

There is no direct effect on individual behavior: $D_{b}$ is unchanged and $b$ and $n$ do not affect individual plans as is clear from equations (T1.1)-(T1.7) in Table 2. There are nevertheless general equilibrium effects because the baby bust results in a decrease in the population growth rate which features prominently in the macroeconomic part of the model consisting of equations (T1.8)-(T1.12) in Table 2. Key indicators of the equilibrium attained after the baby bust are reported in column (f) of Table 4 and in column ( $\mathrm{g}$ ) of Table 5. In contrast to the longevity boost, the baby bust produces only relatively small effects on most variables. Schooling and the retirement age increase by, respectively, 0.11 and 0.58 years, and the working career $(R-E)$ is extended by about half of 1 year. The stock of physical capital increases by $0.29 \%$ whilst the human capital stock and output fall by, respectively, 1.35 and $0.97 \%$.

\section{Robustness Checks}

In the previous section we have shown that of the prototypical ageing shocks that have hit modern economies in recent times, the longevity boosts exert quantitatively major effects on factors supplies and on output, whereas the effects of a baby bust are very modest. In this section we examine the robustness of these conclusions by relaxing a number of the key assumptions underlying the base model. First, in Sect. 4.1 we drop the assumption of perfect capital markets and postulate that individuals face binding borrowing constraints after leaving school. Second, in Sect. 4.2 we introduce indivisi- 
bility of labour into the base model and show how life-cycle plans and macroeconomic outcomes are affected both qualitatively and quantitatively.

\subsection{Borrowing Constraints}

As is clear from the scaled asset profile in Fig. 3d, an optimizing individual is indebted for more than 20 years during the first part of his/her life. In the base model capital markets are perfect and individuals are freely able to borrow against future wage income. In this subsection we investigate the qualitative and quantitative importance of this capital market assumption. ${ }^{12}$ In the trivial case, without any borrowing allowed whatsoever, the constraint is bound to have major effects because a positive amount of schooling would be prohibitively unattractive as the agent has no income during the schooling period and consumption is essential. ${ }^{13}$

We study a less drastic capital market imperfection by assuming that there exists a perfect system of study loans during the schooling period and a prohibition on borrowing after leaving school. ${ }^{14}$ Two regimes can be distinguished, depending on whether or not the borrowing constraint is binding. If the constraint does not bind, then the optimal paths for consumption and leisure are limited only by a present-value constraint just as in the base model. We refer to this as the (Irving) Fisher Regime, after its principal architect. In contrast, if the borrowing constraint is binding, then the paths for consumption and leisure are limited by the availability of non-asset income, i.e. a flow constraint is relevant in that case. We call this the (John Maynard) Keynes Regime. $^{15}$

In our extended model the life-cycles dates are as follows. The educational phase is Fisherian and lasts for ages $0 \leq u<E$. It is followed by the Keynesian employment phase for $E \leq u<F$, where $F$ stands for the age at which the constraint on borrowing first ceases to bind. The remainder of life is Fisherian and consists of an employment phase $(F \leq u<R)$ and a retirement phase $\left(R \leq u \leq D_{b}\right)$.

\footnotetext{
12 An earlier macroeconomic literature investigates the effects of borrowing constraints on the economic growth rate. See, for example, Jappelli and Pagano (1994, 1999) and De Gregorio (1996).

13 Solving the base model under the life-time borrowing constraint yields: $E=0, R=48.875, \Lambda\left(v_{0}\right)=$ $-12.715, y=0.839, k=1.854, h c=0.367, \tilde{w}=1.747$, and $100 \times r=3.637$. Compared to the base model, physical and human capital stocks fall by, respectively, 5.37 and $19.17 \%$, whilst output drops by $16.12 \%$. Wages rise because human capital get scarcer. The borrowing constraint ceases to be binding at biological age 32.382 , i.e. agents are constrained throughout their youth.

14 We call this a perfect system because students can borrow as much as they like at the going market rate of interest, restrained only by the requirement that they redeem their study debt upon leaving school. In the absence of borrowing constraints after leaving school the study loan system is completely neutral-see below. For a more extensive quantitative analysis of different study loans systems in a stochastic setting, see Heijdra et al. (2014a).

15 Weiss (1972) uses the terminology Jevons phase and Ramsey phase for, respectively, our Keynesian and Fisherian Regimes. In our view the notion of consumption being constrained by the flow of income is most closely associated with Keynes. Furthermore, the dynamic approach to individual saving was pioneered by Fisher.
} 


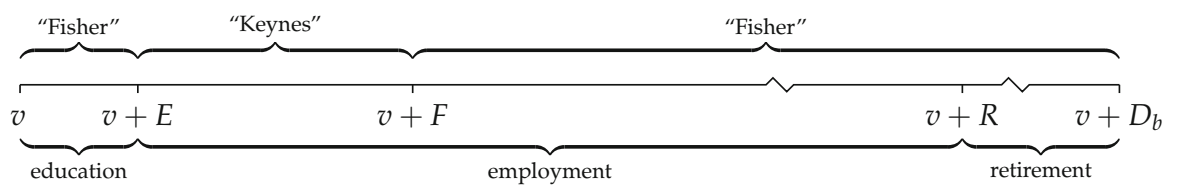

The study loans system works as follows. During the schooling period $(0 \leq t-v<$ $E$ ) the agent can borrow freely at the given interest rate $r$ and thus accumulates study debt according to:

$$
\dot{s}(v, t)=r s(v, t)+c(v, t),
$$

where $s(v, v)=0$ as the students enters the system with a clean slate. Upon completion of the educational period the agent is faced with a study debt of $s(v, v+E)$ which must be paid off over the remaining lifetime. Hence, for $E \leq t-v<D_{b}$ the accumulation identity for study loans is given by:

$$
\dot{s}(v, t)=r s(v, t)-i(v), \quad \text { such that } s\left(v, v+D_{b}\right)=0,
$$

where $i(v)$ is the periodic redemption payment which we assume for simplicity sake to be age-independent. In present value terms the system of study loans imposes the following constraint of the agent:

$$
i(v)=\frac{r}{1-e^{-r\left(D_{b}-E\right)}} \int_{v}^{v+E} c(v, t) e^{-r(t-v-E)} d t .
$$

In the Fisherian regime $\left(F \leq t-v \leq D_{b}\right)$ regular financial assets evolve according to:

$$
\dot{a}(v, t)=r a(v, t)+w(t) l(v, t) h(v, t)-c(v, t)-i(v),
$$

with $a(v, v+F)=a\left(v, v+D_{b}\right)=0$ so that the present-value constraint is given by:

$$
\int_{v+F}^{v+R} w(t) l(v, t) h(v, t) e^{-r(t-v)} d t=\int_{v+F}^{v+D_{b}}[c(v, t)+i(v)] e^{-r(t-v)} d t .
$$

Equation (5b) replaces (2c) and differs from it because (i) $F>E>0$ and (ii) redemption payments feature on the right-hand side. ${ }^{16}$

The agent chooses $E, F, R, i(v),\{c(v, \tau)\}_{\tau=v}^{v+D_{b}}$, and $\{l(v, \tau)\}_{\tau=v}^{v+D_{b}}$ in order to maximize lifetime utility (2a) subject to the present-value budget constraints (5a) and (5b), and the human capital equation (2e ). The optimal choices for consumption are given by:

$$
\begin{aligned}
\Phi_{c}(c(v, t), z(v, t)) & =\xi(v) \frac{r e^{r E}}{1-e^{-r\left(D_{b}-E\right)}} e^{-(r-\rho)(t-v)} \quad 0 \leq t-v<E, \quad E \leq t-v<F \\
c(v, t) & =w(t) l(v, t) h(v, t)-i(v) \quad E \\
\Phi_{c}(c(v, t), z(v, t)) & =\lambda(v) e^{-(r-\rho)(t-v)} \quad F \leq t-v \leq D_{b}
\end{aligned}
$$

\footnotetext{
16 If there were no constraint on the sign of regular assets then the study loan system would be completely neutral. Indeed, in such a case the integrals in (5b) would run from $E$ instead of $F$. In combination with (5a) the resulting expression would yield (2c).
} 
where $\xi(v)$ and $\lambda(v)$ are the Lagrange multipliers for, respectively, (5a) and (5b). Consumption grows at the exponential rate $\sigma^{*}(r-\rho)$ in the two Fisherian regimes, just as in the base model, but during the Keynesian employment regime wage income net of redemption payments dictates the path of consumption.

The first-order condition for the redemption payment furnishes the following relationship between $\xi(v)$ and $\lambda(v)$ :

$$
\xi(v)=\lambda(v)\left[\int_{v+E}^{v+F} \Psi(v, \tau) e^{-r(\tau-v)} d \tau+e^{-r E} \frac{1-e^{-r\left(D_{b}-E\right)}}{r}\right],
$$

where $\Psi(v, \tau)$ is a "distortion" term originating from the borrowing constraint:

$$
\Psi(v, \tau) \equiv \frac{\Phi_{c}(c(v, \tau), z(v, \tau))-\lambda(v) e^{-(r-\rho)(\tau-v)}}{\lambda(v) e^{-(r-\rho)(\tau-v)}}, \quad E \leq t-v \leq D_{b}
$$

Clearly, in view of (5d)-(5e), $\Psi(v, \tau)>0$ for $E \leq t-v<F$ and $\Psi(v, \tau)=0$ for $F \leq t-v \leq D_{b}$. Intuitively, the agent would like to consume more in the Keynesian employment regime but the borrowing constraint prohibits this from happening. In contrast, in the Fisherian employment and retirement regimes the agent faces no borrowing constraint and there is thus no distortion in the consumption choice.

The first-order condition for labour supply can be written as follows:

$$
\begin{aligned}
\Phi_{z}(c(v, t), z(v, t))= & \lambda(v) e^{-(r-\rho)(t-v)[w(t) h(v, t)+\gamma V(v, t)} \\
& +\gamma \int_{t}^{v+D_{b}} \Psi(v, \tau) w(\tau) l(v, \tau) h(v, \tau) e^{-r(\tau-t)} d \tau \\
& +\Psi(v, t) w(t) h(v, t)], \quad E \leq t-v \leq R .
\end{aligned}
$$

The first line coincides with the expression obtained for the base model (see equation (3b) above), whilst the second and third line show the effects of the borrowing constraint on labour supply in the Keynesian regime. In this regime the agent partially relaxes the consumption-reducing effect of the borrowing constraint by supplying more hours of labour than he/she would in the absence of this restriction.

The first-order condition for the education decision is given by:

$$
\begin{aligned}
& \Phi\left(c\left(v, v+E^{-}\right), 1-e_{0}\right)-\Phi(c(v, v+E), 1-l(v, v+E)) \\
& =\lambda(v) e^{-(r-\rho) E}\left[w(v+E) l(v, v+E) h(v, v+E)+\left(c\left(v, v+E^{-}\right)-c(v, v+E)\right)\right. \\
& \quad-\int_{v+E}^{v+R} w(\tau) l(v, \tau) \frac{\partial h(v, \tau)}{\partial E} e^{-r(\tau-v-E)} d \tau \\
& \quad+\Psi\left(v, v+E^{-}\right)\left[w(v+E) l(v, v+E) h(v, v+E)+\left(c\left(v, v+E^{-}\right)-c(v, v+E)\right)\right] \\
& \left.\quad-\int_{v+E}^{v+F} \Psi(v, \tau) w(\tau) l(v, \tau) \frac{\partial h(v, \tau)}{\partial E} e^{-r(\tau-v-E)} d \tau\right] .
\end{aligned}
$$


Compared to the corresponding condition in the base model $((3 \mathrm{e}))$, the expression in (5i) is much more complicated because the distortion term $\Psi(v, \tau)$ affects all three components constituting the marginal utility cost of schooling.

Finally, the first-order conditions for $F$ and $R$ just impose there to be no discontinuities in consumption and labour supply at these points in the life cycle.

The quantitative effects of borrowing constraints can be gleaned from columns (g)(h) in Table $4 .{ }^{17}$ For ease of comparison, column (a) restates the calibrated base model. Comparing columns (a) and (g) we find the partial equilibrium effects of the capital market imperfection. Optimal schooling is virtually unaffected and retirement occurs at a slightly earlier age. Even though the agent faces a binding borrowing constraint and is forced to underconsume for almost 4.5 years, life-time utility is reduced only by a tiny amount.

Not surprisingly, in view of the minute partial equilibrium effects, factor price changes are rather modest and the partial and general equilibrium effects of the capital market imperfection are very similar. Comparing columns (a) and (h) we find that output and the stock of physical capital increase by, respectively, $0.13 \%$ and $0.65 \%$, whereas the stock of human capital falls by $0.03 \%$. Life-time utility rises slightly because the increase in the ratio between physical and human capital leads to a reduction in the interest rate thus bringing the economy closer to the Golden Rule point (featuring $r=n$ ).

From a quantitative perspective the conclusion seems warranted that the system of study loans postulated here virtually eliminates the unpleasant aspects of the constraints on borrowing. It removes the teeth from the dragon of capital market imperfections. By insulating young agents from this form of market imperfection, the process of human capital formation is saved from otherwise inevitable destruction. The borrowing constraints that hinder agents during the employment period are quantitatively unimportant.

Figure 6 visualizes some of the life-cycle profiles in the presence of borrowing constraints. Panel (a) shows that the agent supplies more hours of labour between ages $E$ and $F$. Intuitively, in doing so he/she builds up human capital more rapidly (see panel (c)) and partially alleviates the constraint on consumption. Panel (b) shows that there is a downward jump in consumption jump at age $E$, for reasons explained above, and that there exists a smooth connection between the Keynesian and Fisherian consumption paths at age $F$. Finally, panel (d) depicts the profiles for scaled regular assets and study debt. An agent's net financial assets become positive a little before reaching biological age 40 .

The quantitative effects of demographic shocks under borrowing constrains are summarized Table 5. Columns (b), (e), and (h) summarize the general equilibrium solutions for, respectively, BLB, CLB, and BB. Interestingly, as the comparison with columns (a), (d), and (g) (the base model results) reveals, the effects of demographic shocks are quantitatively very similar with and without borrowing constraints. Indeed, even in the absence of study loans, with agents facing life-time borrowing constraints, exactly the same conclusion is obtained. Economies with and without borrowing con-

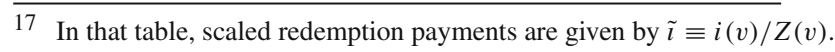



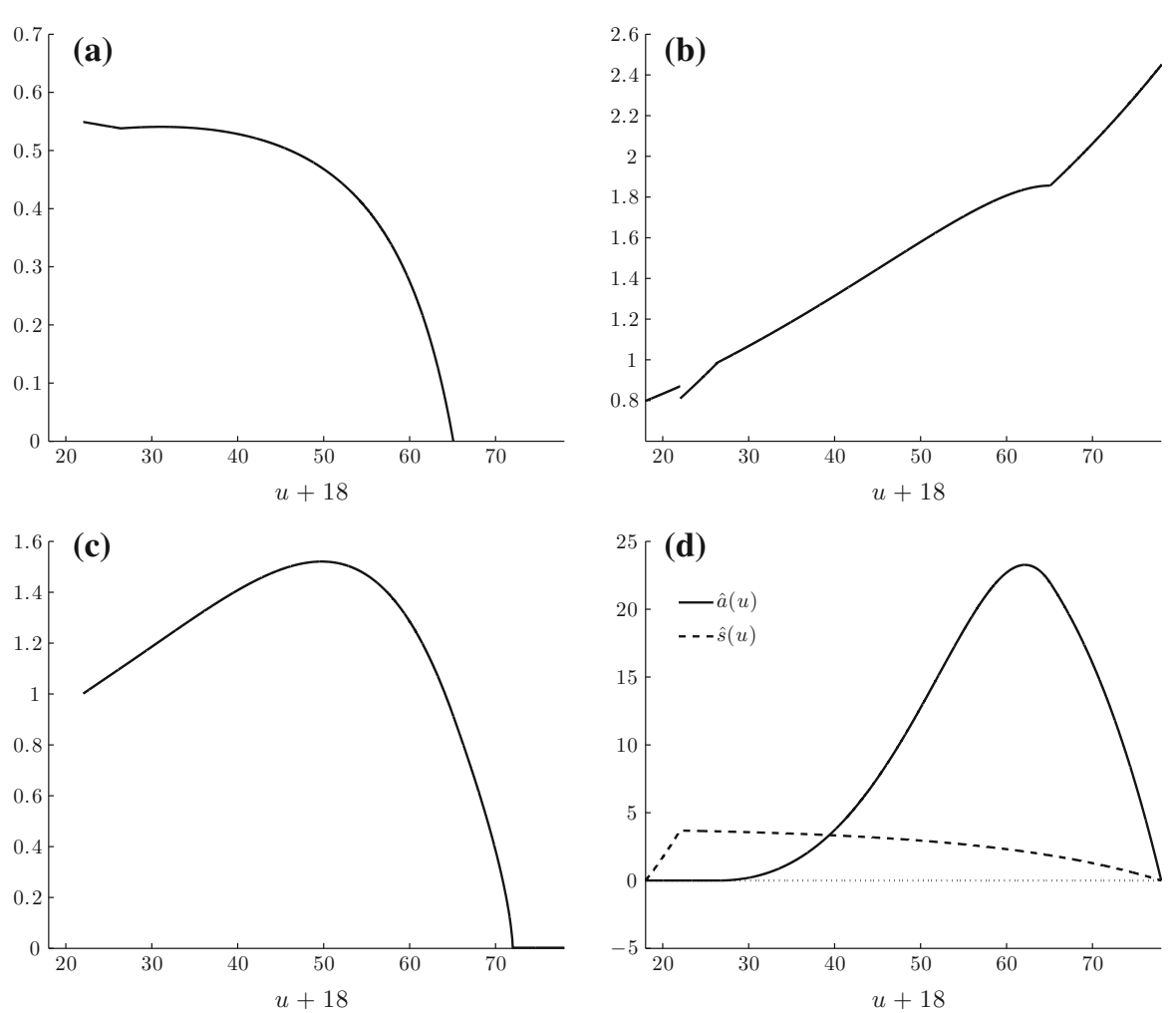

Fig. 6 Life-cycle profiles in the presence of borrowing constraints. a Labour supply, $l(u)$. b Scaled consumption, $\tilde{c}(u)$. c Human capital, $h(u)$. d Scaled assets and study debt, $\tilde{a}(u)$ and $\tilde{s}(u)$

straints react in a very similar way to the ageing shocks that we have considered in this paper.

\subsection{Indivisible Labour}

In the base model labour supply is fairly constant over much of the agent's life but declines sharply after age 50. Labour is perfectly divisible so retirement from the labour force takes the form of a gradual reduction in working hours. In reality, however, parttime jobs of the right magnitude are very hard to find or even completely absent from the economic menu. In this subsection we therefore investigate the qualitative and quantitative importance of the assumption regarding divisibility of labour. ${ }^{18}$ In particular we assume that an individual can either work full time (and choose $l(v, t)=$ $l_{F}$ ) or not at all (by setting $l(v, t)=0$ ). Whilst it is—in principle-straightforward to recognize a finer grid of employment choices (such as half-time jobs), we employ the 2-state model because, first, it is well established in the macroeconomic literature

18 See also Mulligan (2001), Prescott et al. (2009), and Ljungqvist and Sargent (2011) on this issue. 


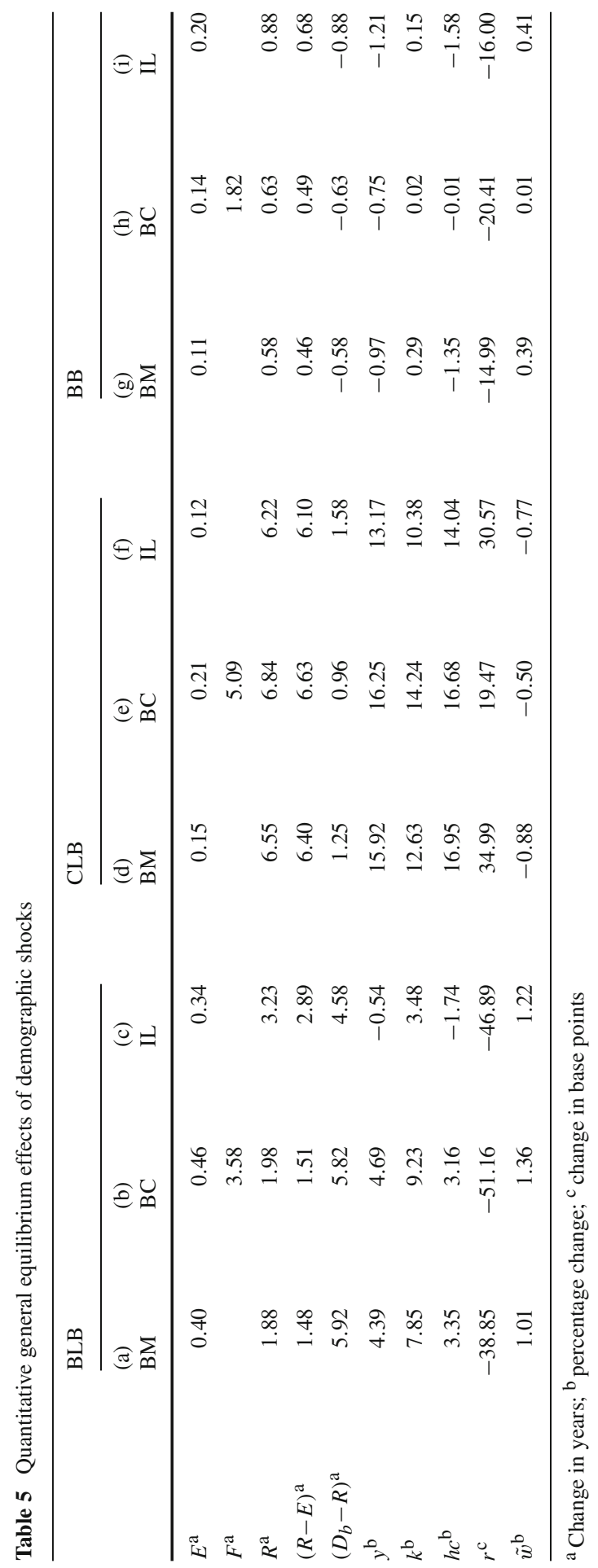


and, second, it gives the cleanest possible representation of the notion of indivisibility of labour supply. We reinstate the assumption of perfect capital markets.

We can already anticipate that in the current (deterministic) set-up the agent will start working full-time directly upon finishing school and will work until a certain age $R$ at which he or she retires completely from the labour force. In the Indivisible Labour (IL hereafter) model, leisure is no longer a choice variable in itself, as it is determined by choices of $E$ and $R$ :

$$
z(v, t)= \begin{cases}1-e_{0} & \text { for } 0 \leq t-v<E \\ 1-l_{F} & \text { for } E \leq t-v<R \\ 1 & \text { for } R \leq t-v \leq D_{b}\end{cases}
$$

whilst the human capital stock evolves according to:

$$
h(v, t)= \begin{cases}e^{G(E)} e^{\gamma l_{F}(t-v-E)-\int_{v+E}^{t} \delta_{h}(\tau-v) d \tau} & \text { for } E \leq t-v<R \\ h(v, v+R) e^{-\int_{v+R}^{t} \delta_{h}(\tau-v) d \tau} & \text { for } R \leq t-v \leq D_{e}\end{cases}
$$

The lifetime budget constraint is given by:

$$
\int_{v+E}^{v+R} w(t) l_{F} h(v, t) e^{-r(t-v)} d t=\int_{v}^{v+D_{b}} c(v, t) e^{-r(t-v)} d t .
$$

In the presence of perfect capital markets, the individual's time line is the same as in the base model. The agent chooses the education level $E$, the retirement age $R$, and a time profile for consumption $\{c(v, \tau)\}_{\tau=v}^{v+D_{b}}$ in order to maximize lifetime utility (2a) subject to the lifetime budget constraint (6c) and the human capital equation (6b). Not surprisingly, since capital markets are perfect, the first-order condition for consumption is still as given in (3a). The optimality conditions for schooling and the retirement age are obtained by setting $l(v, t)=l_{F}$ for $E \leq t-v<R$ and $l(v, t)=0$ for $R \leq t-v \leq D_{b}$ in, respectively, (3e) and (3f):

$$
\begin{aligned}
& \Phi\left(c\left(v, v+E^{-}\right), 1-e_{0}\right)-\Phi\left(c(v, v+E), 1-l_{F}\right) \\
& =\lambda(v) e^{-(r-\rho) E}\left[w(v+E) l_{F} h(v, v+E)\right. \\
& \left.\quad-\int_{v+E}^{v+R} w(t) l_{F} \frac{\partial h(v, t)}{\partial E} e^{-r(t-v-E)} d t+\left(c\left(v, v+E^{-}\right)-c(v, v+E)\right)\right], \\
& \Phi\left(c\left(v, v+R^{-}\right), 1-l_{F}\right)-\Phi(c(v, v+R), 1) \\
& \quad=\lambda(v) e^{-(r-\rho) R}\left[-w\left(v+R^{-}\right) l_{F} h\left(v, v+R^{-}\right)+\left(c\left(v, v+R^{-}\right)-c(v, v+R)\right)\right] .
\end{aligned}
$$

As a consequence of the indivisibility of labour, the consumption jumps (3b) and ( $3 g$ ) are replaced by: 

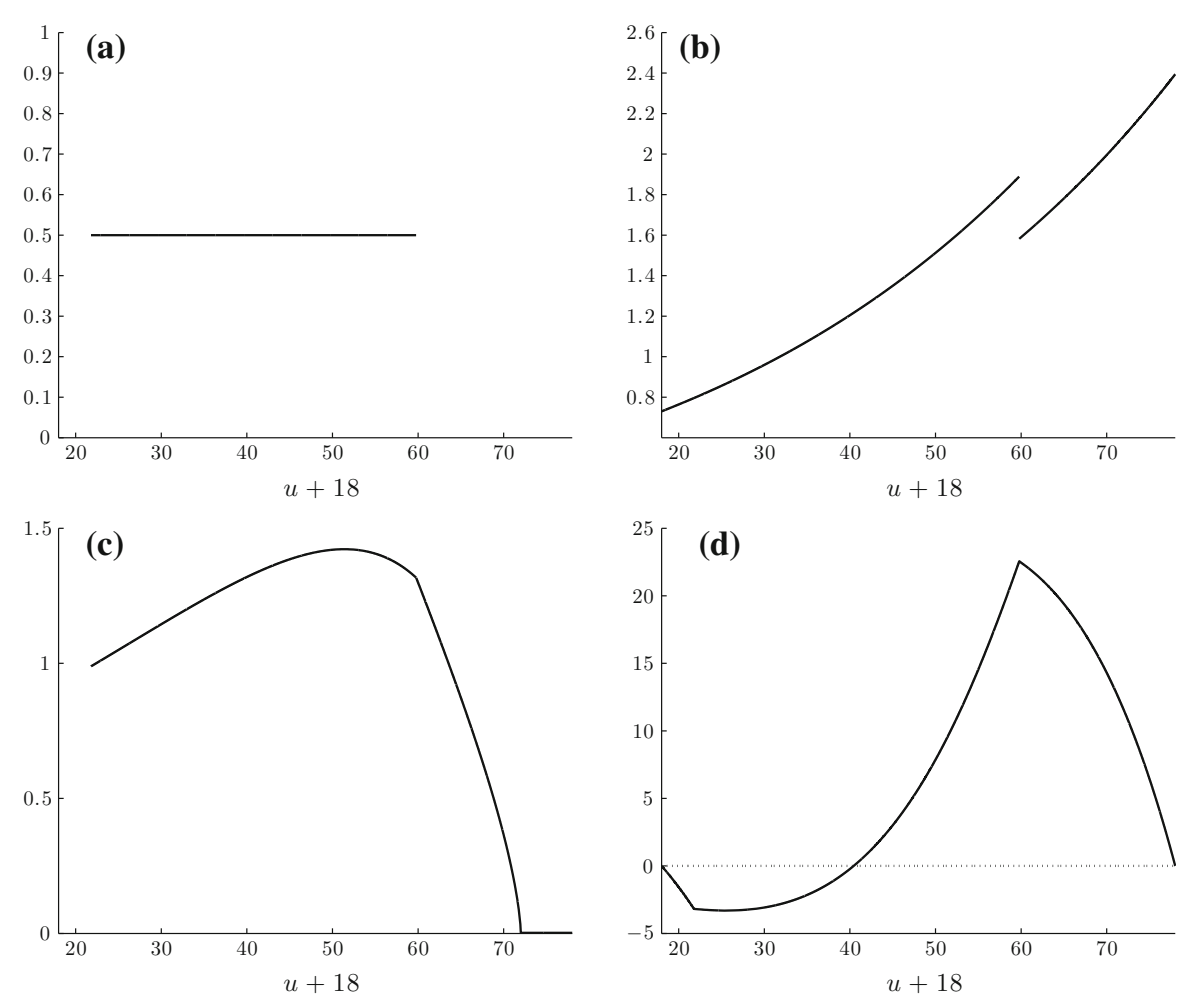

Fig. 7 Life-cycle profiles with indivisible labour. a labour supply, $l(v)$. b Scaled consumption, $\tilde{c}(u)$. c Human capital, $h(u)$. d Scaled financial assets, $\tilde{a}(u)$

$$
\frac{c(v, v+E)}{c\left(v, v+E^{-}\right)}=\left(\frac{1-e_{0}}{1-l_{F}}\right)^{\frac{(1-\sigma) \varepsilon_{z}}{1-\varepsilon_{z}(1-\sigma)}}, \quad \frac{c(v, v+R)}{c\left(v, v+R^{-}\right)}=\left(\frac{1-l_{F}}{1}\right)^{\frac{(1-\sigma) \varepsilon_{z}}{1-\varepsilon_{z}(1-\sigma)}}
$$

The quantitative effects of the indivisibility constraints can be gleaned from columns (i)-(j) in Table 4. We assume that $l_{F}=0.5$ represents a full-time job. For ease of comparison, column (a) restates the calibrated base model. Comparing columns (a) and (i) we find the partial equilibrium effects of the labour market imperfection. Optimal schooling is reduced by a mere 0.15 years but retirement takes place as much as 4.74 years earlier. Since gradual retirement is ruled out, consumption features a sizeable downward jump at age $R$ and life-time utility is reduced substantially.

The general equilibrium effects of the labour market imperfection on $E$ and $R$ are very similar to their partial equilibrium counterparts. Comparing columns (a) and (j) we find that output and the stocks of physical and human capital decrease by, respectively, $6.40,7.04$ and $6.16 \%$. Since the ratio between physical and human capital falls, there is a slight increase in the interest rate and decrease in the scaled wage rate.

Figure 7 visualizes some of the life-cycle profiles in the presence of IL constraints. Panel (a) shows that the agent supplies $l_{F}$ hours of labour between ages $E$ and $R$. Panel (b) shows that there is a substantial downward jump in consumption jump at 
age $R$, for reasons explained above-see (6f). The consumption path is continuous at age $E$ because - by assumption — students spend a full work day on education, so that $e_{0}=l_{F}$. Panels (c) and (d) show that the indivisibility of labour introduces sharp kinks in the profiles for human capital and financial wealth.

The quantitative effects of demographic shocks under indivisible labour constraints are given in Table 5. Columns (c), (f), and (i) summarize the general equilibrium solutions for, respectively, BLB, CLB, and BB. The comparison with columns (a), (d), and (g) reveal two main conclusions. First, the effects of the CLB and BB are quantitatively rather similar with and without the labour market imperfection. Second, the effects of the BLB are somewhat different under the IL constraint. Compared to the base model retirement is later, the increase in the capital stock is much smaller, and both human capital and output fall. The movement of factor prices is still in line with the results obtained in the base model. We conclude that even though economies with and without perfect divisibility of labour are quite different, they react in a very similar way to the ageing shocks that we have studied in this paper.

\section{Conclusions}

We study the steady-state general equilibrium effects of a number of stylized ageing shocks that have hit most western economies in one form or another over the last half century. In order to do so we formulate an overlapping generations model of a closed economy featuring endogenous factor prices. We generalize the classic "certain death" framework of Cass and Yaari (1967) by assuming that individual agents accumulate both physical and human capital. In the tradition of the recent human capital literature we assume that individuals engage in full-time educational activities at the start of economic life and choose the optimal age of labour market entry. Incorporating the insights of the empirical literature on Mincerian wage equations, we assume that participating in the labour market boosts a worker's human capital stock as valuable experience is gained. As a worker gets older, economic ageing sets in because human capital starts to depreciate at an increasing rate. This prompt the rational individual to ultimately retire from the labour force.

The first ageing shock that we consider is a purely biological one taking the form of an increase in the age of death. Holding constant the growth rate of the population this results in a decrease in the crude birth rate and increase in the old-age dependency ratio. In response to the longer lifetime, agents choose more schooling, retire later, and increase the length of the work career. Almost all of the additional years of life are consumed in the form of leisure as the retirement period increases substantially. At the macroeconomic level the stocks of physical and human capital both rise, with the former increase dominating the latter. Human capital becomes relatively scarce under the biological longevity boost (BLB) prompting an increase in its rental rate and a decrease in the interest rate. The intuition behind this result is that the human capital depreciation schedule is kept unchanged under the BLB. So even though individuals enjoy a longer biological life, their economic life is unaffected.

The second ageing shock is a comprehensive longevity boost (CLB) in which both biological and economic lifetimes are lengthened. In this case the stocks of physical 
and human capital both rise sharply, with the latter increase dominating the former. Schooling is increased only slightly, but as retirement takes place much later on in life, the length of the work career rises dramatically. Surprisingly, the optimal retirement period is decreased under the CLB, i.e. the additional years of biological life are not spent on leisure but on working. Under the comprehensive longevity boost wages fall and the real interest rises in the long run. By separately distinguishing biological and economic longevity we are thus able to demonstrate that factor prices may move in a direction opposite to the one accepted as conventional wisdom in the existing literature.

The third ageing shock is a baby bust (BB) scenario in which there is an exogenous decrease in the net birth rate. For a given length of biological life, this implies that the growth rate of the population and the crude birth rate both decrease whilst the old-age dependency ratio increases. Interestingly, the quantitative effects of this shock are rather small. The slight increase in the physical capital stock is accompanied by a small decrease in the stock of human capital leaving macroeconomic output virtually unchanged.

Our results are based on a plausibly calibrated numerical version of our theoretical model. To demonstrate the robustness of our conclusions to alternative modelling assumptions we also study two extensions. The first extension introduces a capital market imperfection. Whereas the resulting constraints on borrowing are potentially disastrous to the educational process, we show that much of the damage can be removed by incorporating a system of study loans for young individuals. Provided such a system exists, the effects of the ageing shocks are very similar to those for the base model.

A second extension introduces a labour market imperfection taking the form of an indivisibility of labour supply. Under the assumption that agents can either work full time or not at all, ageing shocks can only affect the worker's participation, i.e. changes take place via the extensive margin. The indivisibility constraint itself causes nontrivial welfare losses to the agent because the desired gradual retirement process is not feasible. Interestingly, the conclusions with respect to the ageing shocks are qualitatively the same and quantitatively rather similar to the ones obtained in the base model.

Despite being a mainly theoretical exercise, our paper yields two very clear lifecycle policy recommendations. First, in the presence of capital market imperfections in the form of borrowing constraints it is vitally important that some kind of study loan system is in place to allow young individuals to invest in their human capital at the start of life. Second, our analysis shows that indivisible labour contracts are very unattractive to older workers as they would much prefer to gradually retire from the labour force.

Open Access This article is distributed under the terms of the Creative Commons Attribution 4.0 International License (http://creativecommons.org/licenses/by/4.0/), which permits unrestricted use, distribution, and reproduction in any medium, provided you give appropriate credit to the original author(s) and the source, provide a link to the Creative Commons license, and indicate if changes were made.

\section{Appendix 1: Properties of the Felicity Function}

Lemma 1 Let the felicity function be defined as: 


$$
\Phi(c, z)=\frac{\left[c^{\varepsilon_{c}} z^{\varepsilon_{z}}\right]^{1-1 / \sigma}-1}{1-1 / \sigma}, \quad 0<\sigma<1, \quad 0<\varepsilon_{c}, \varepsilon_{z}<1, \quad \varepsilon_{c}+\varepsilon_{z}=1
$$

Subfelicity over consumption and leisure is of the Cobb-Douglas form while the overall felicity function belongs to the CRRA class with a constant intertemporal substitution elasticity $\sigma$. The following properties can be established.

(i) Felicity is non-separable in consumption and leisure in that the marginal felicity of consumption depends on leisure and vice versa:

$$
\Phi_{c}(c, z)=\frac{\varepsilon_{c}}{c}\left[c^{\varepsilon_{c}} z^{\varepsilon_{z}}\right]^{1-1 / \sigma}>0, \quad \Phi_{z}(c, z)=\frac{\varepsilon_{z}}{z}\left[c^{\varepsilon_{c}} z^{\varepsilon_{z}}\right]^{1-1 / \sigma}>0 .
$$

(ii) Consumption and leisure are direct substitutes, i.e. an increase in consumption lowers the marginal felicity of leisure and vice versa:

$$
\Phi_{c z}(c, z)=\Phi_{z c}(c, z)=-\frac{1-\sigma}{\sigma} \frac{\varepsilon_{c}}{c} \frac{\varepsilon_{z}}{z}\left[c^{\varepsilon_{c}} v^{\varepsilon_{v}}\right]^{1-1 / \sigma}<0 .
$$

(iii) The marginal rate of substitution between consumption and leisure is not affected by the intertemporal substitution elasticity for subfelicity:

$$
\frac{\Phi_{z}(c, z)}{\Phi_{c}(c, z)}=\frac{\varepsilon_{z}}{\varepsilon_{c}} \frac{c}{z} \text {. }
$$

(iv) The intertemporal substitution elasticity for consumption is given by:

$$
\sigma^{*} \equiv-\frac{\Phi_{c}(c, z)}{c \Phi_{c c}(c, z)}=\frac{\sigma}{1-\varepsilon_{z}(1-\sigma)},
$$

where $\sigma<\sigma^{*}<1$.

Proof Straightforward by differentiation.

\section{Appendix 2: Demographic Function}

Lemma 2 (Properties of the exponential function) For $x \neq 0$ we have:

$$
e^{x}>1+x
$$

Proof Define $f(x) \equiv e^{x}-(1+x)$. Then $f^{\prime}(x)=e^{x}-1$ is positive for all $x>0$, zero for $x=0$, and negative for all $x<0$. Hence, the function $f(x)$ reaches its global minimum of 0 at $x=0$ and is strictly positive elsewhere.

Lemma 3 (Properties of the demographic function) The demographic function (4b) has the following properties:

(i) Positive, $\Delta(n, T)>0$. 
(ii) Decreasing in $n, \partial \Delta(n, T) / \partial n<0$.

(iii) Increasing in $T, \partial \Delta(n, T) / \partial T>0$.

Proof Part (i) follows from the definition of the demographic function as $0<T \ll \infty$ and $e^{-n T} \lessgtr 1$ for $n \gtrless 0$. The first derivatives are given by:

$$
\begin{aligned}
& \Delta_{n}(n, T) \equiv \frac{\partial \Delta(n, T)}{\partial n}= \begin{cases}-\frac{e^{n T}-[1+n T]}{n^{2} e^{n T}} & \text { for } n \neq 0 \\
-\frac{T^{2}}{2} & \text { for } n=0\end{cases} \\
& \Delta_{T}(n, T) \equiv \frac{\partial \Delta(n, T)}{\partial T}= \begin{cases}e^{-n T} & \text { for } n \neq 0 \\
1 & \text { for } n=0\end{cases}
\end{aligned}
$$

Applying Lemma 2 establishes part (ii) in case $n \neq 0$. Part (iii) is straightforward given the expression for $\Delta_{T}(n, T)$.

Proposition 1 (Features of the demographic structure) Consider the demographic structure as stated in Sect. 2.3. Let $u_{\mathrm{old}}$ denote the age beyond which one is considered old. Define the old-age dependency ratio as:

$$
d r \equiv \frac{\int_{u_{\mathrm{old}}}^{D_{b}} p(v, v+u) d u}{\int_{0}^{u_{\mathrm{old}}} p(v, v+u) d u}
$$

Then the following properties can be established.

(i) Ceteris paribus, an increase in the length of life $D_{b}$ :

- does not affect the population growth rate $n$;

- decreases the crude birth rate $\bar{b}$;

- and increases the dependency ratio $d r$.

(ii) Ceteris paribus, a decrease in the net birth rate b:

- decreases the population growth rate $n$;

- decreases the crude birth rate $\bar{b}$;

- and increases the dependency ratio $d r$.

Proof Take $B$ as exogenously fixed and choose a value for $b$ and $D_{b}$. Then the population growth rate $n$ follows from the demographic steady-state condition (4a). Applying the Implicit Function Theorem gives:

$$
\frac{\partial n}{\partial b}=-\frac{\Delta(n, B)^{2}}{\Delta_{n}(n, B)}>0 .
$$

Given $n$, the crude birth rate $\bar{b}$ is implicitly defined as:

$$
1=\bar{b} \Delta\left(n, D_{b}\right)
$$


such that:

$$
\frac{\partial \bar{b}}{\partial n}=-\frac{\Delta_{n}\left(n, D_{b}\right)}{\Delta\left(n, D_{b}\right)^{2}}>0, \quad \frac{\partial \bar{b}}{\partial D_{b}}=-\frac{\Delta_{T}\left(n, D_{b}\right)}{\Delta\left(n, D_{b}\right)^{2}}<0 .
$$

The chain rule then gives:

$$
\frac{\partial \bar{b}}{\partial b}=\frac{\partial \bar{b}}{\partial n} \frac{\partial n}{\partial b}>0
$$

We can write the dependency ratio as:

$$
d r= \begin{cases}\frac{1-e^{-n\left(D_{b}-u_{\mathrm{old}}\right)}}{e^{n u_{\mathrm{old}}}-1} & \text { for } n \neq 0 \\ \frac{D_{b}-u_{\mathrm{old}}}{u_{\mathrm{old}}} & \text { for } n=0\end{cases}
$$

such that:

$$
\begin{aligned}
& \frac{\partial d r}{\partial D_{b}}= \begin{cases}\frac{n e^{-n\left(D_{b}-u_{\mathrm{old}}\right)}}{e^{n u_{\mathrm{old}}}-1}>0 & \text { for } n \neq 0 \\
\frac{1}{u_{\mathrm{old}}}>0 & \text { for } n=0\end{cases} \\
& \frac{\partial d r}{\partial n}= \begin{cases}\frac{e^{n\left[u_{\mathrm{old}}-\left(D_{b}-u_{\mathrm{old}}\right)\right]}\left\{D_{b}-\left(D_{b}-u_{\mathrm{old}}\right) e^{-n u_{\mathrm{old}}}-u_{\mathrm{old}} e^{n\left(D_{b}-u_{\mathrm{old}}\right)}\right\}}{\left(D_{b}-u_{\mathrm{old}}\right) D_{b}}<0 & \text { for } n \neq 0 \\
-\frac{\left(e^{n u_{\mathrm{old}}}-1\right]^{2}}{2 u_{\mathrm{old}}}<0 & \text { for } n=0\end{cases}
\end{aligned}
$$

where the sign in the latter case follows by applying Lemma 2. Combining yields:

$$
\frac{\partial d r}{\partial b}=\frac{\partial d r}{\partial n} \frac{\partial n}{\partial b}<0
$$

\section{References}

Attanasio, O. P., \& Weber, G. (1995). Is consumption growth consistent with intertemporal optimization? Evidence from the consumer expenditure survey. Journal of Political Economy, 103, 1121-1157.

Ben-Porath, Y. (1967). The production of human capital and the life cycle of earnings. Journal of Political Economy, 75, 352-365.

Blinder, A. S., \& Weiss, Y. (1976). Human capital and labor supply: A synthesis. Journal of Political Economy, 84, 449-472.

Bloom, D. E., Canning, D., Mansfield, R. K., \& Moore, M. (2007). Demographic change, social security systems, and savings. Journal of Monetary Economics, 54, 92-114.

Boucekkine, R., de la Croix, D., \& Licandro, O. (2002). Vintage human capital, demographic trends, and endogenous growth. Journal of Economic Theory, 104, 340-375.

Cass, D., \& Yaari, M. E. (1967). Individual saving, aggregate capital accumulation, and efficient growth. In K. Shell (Ed.), Essays on the theory of optimal economic growth. Cambridge, MA: MIT Press. 
De Gregorio, J. (1996). Borrowing constraints, human capital accumulation, and growth. Journal of Monetary Economics, 37, 49-71.

de la Croix, D., \& Licandro, O. (1999). Life expectancy and endogenous growth. Economics Letters, 65, 255-263.

Driffill, E. J. (1980). Life-cycles with terminal retirement. International Economic Review, 21, 45-62.

Heckman, J. J. (1974). Life cycle consumption and labour supply: An explanation of the relationship between income and consumption over the life cycle. American Economic Review, 64, 188-194.

Heckman, J. J. (1976). A life-cycle model of earnings, learning, and consumption. Journal of Political Economy, 84, S11-S44.

Heckman, J. J., Lochner, L., \& Todd, P. (2006). Earnings functions, rates of return and treatment effects: The Mincer equation and beyond. In E. A. Hanushek \& F. Welch (Eds.), Handbook of the Economics of Education (Vol. 1). Amsterdam: North-Holland.

Heijdra, B. J., Kindermann, F., \& Reijnders, L. S. M. (2014a). Life in shackles? The quantitative implications of reforming the educational loan system. Working paper 5013, CESifo, München.

Heijdra, B. J., \& Ligthart, J. E. (2006). The macroeconomic dynamics of demographic shocks. Macroeconomic Dynamics, 10, 349-370.

Heijdra, B. J., Mierau, J. O., \& Reijnders, L. S. M. (2014b). A tragedy of annuitization? Longevity insurance in general equilibrium. Macroeconomic Dynamics, 18, 1607-1634.

Heijdra, B. J., \& Reijnders, L. S. M. (2015). Longevity shocks with age-dependent productivity growth. Working paper 5364, CESifo, München.

Heijdra, B. J., \& Romp, W. E. (2009). Human capital formation and macroeconomic performance in an ageing small open economy. Journal of Economic Dynamics and Control, 33, 725-744.

Imai, S., \& Keane, M. P. (2004). Intertemporal labor supply and human capital accumulation. International Economic Review, 45, 601-641.

Jappelli, T., \& Pagano, M. (1994). Saving, growth, and liquidity constraints. Quarterly Journal of Economics, 109, 83-109.

Jappelli, T., \& Pagano, M. (1999). The welfare effects of liquidity constraints. Oxford Economic Papers, $51,410-430$.

Kalemli-Ozcan, S., Ryder, H. E., \& Weil, D. N. (2000). Mortality decline, human capital investment, and economic growth. Journal of Development Economics, 62, 1-23.

Keane, M., \& Rogerson, R. (2012). Micro and macro labor supply elasticities: A reassessment of conventional wisdom. Journal of Economic Literature, 50(2), 464-476.

King, R. G., Plosser, C. I., \& Rebelo, S. (2002). Production, growth and business cycles: Technical appendix. Computational Economics, 20, 87-116.

Ljungqvist, L., \& Sargent, T. J. (2011). A labor supply elasticity accord? American Economic Review, Papers \& Proceedings, 101, 487-491.

Ludwig, A., Schelkle, T., \& Vogel, E. (2012). Demographic change, human capital and welfare. Review of Economic Dynamics, 15, 94-107.

Mulligan, C. B. (2001). Aggregate implications of indivisible labor. Advances in Macroeconomics, 1(1) (Article 4).

Pfeiffer, F., \& Reuss, K. (2008). Age-dependent skill formation and returns to education. Labour Economics, $15,631-646$.

Prescott, E. C., Rogerson, R., \& Wallenius, J. (2009). Lifetime aggregate labor supply with endogenous workweek length. Review of Economic Dynamics, 12, 23-36.

Prettner, K., \& Canning, D. (2014). Increasing life expectancy and optimal retirement in general equilibrium. Economic Theory, 56, 191-217.

Rosen, S. (1972). Learning and experience in the labour market. Journal of Human Resources, 7, 326-342.

Shaw, K. L. (1989). Life-cycle labor supply with human capital accumulation. International Economic Review, 30, 431-456.

Skinner, J. (1985). The effect of increased longevity on capital accumulation. American Economic Review, $75,1143-1150$.

Weiss, Y. (1972). On the optimal lifetime pattern of labour supply. Economic Journal, 82(328), 1293-1315. 